\title{
Surface Grafting of Polymers onto Nanoparticles in a Solvent-Free Dry-System and Applications of Polymer-grafted Nanoparticles as Novel Functional Hybrid Materials
}

\author{
Norio TsUBOKAWA ${ }^{\dagger}$ \\ Department of Material Science and Technology, Faculty of Engineering, \\ Niigata University and Center for Transdisciplinary Research, Niigata University, \\ 8050, Ikarashi 2-nocho, Nishi-ku, Niigata 950-2181, Japan
}

(Received May 7, 2007; Accepted June 1, 2007; Published July 10, 2007)

\begin{abstract}
For the prevention of environmental pollution and simplification of reactions, scale-up synthesis of polymer-grafted inorganic nanoparticles in a solvent-free dry-system is reviewed. The grafting of polymers onto nanoparticles in a solvent-free dry-system was achieved by spraying monomers onto nanoparticles having initiating group. After the reaction, unreacted monomer and by-products were removed under high vacuum. For example, grafting of hyperbranched poly(amidoamine) (PAMAM) was successfully achieved using dendrimer synthesis methodology in a solvent-free dry-system. The percentage of PAMAM grafting onto the nanoparticle surface was $141 \%$ with repeated reaction cycles of 8-times. In addition, radical graft polymerization of vinyl monomers onto silica nanoparticles was achieved by spraying the monomers onto silica nanoparticles containing azo and peroxycarbonate groups in a solvent-free dry-system. The formation of ungrafted polymer was depressed in comparison with graft polymerization in solution: the grafting efficiency was 90-95\%. PAMAM-grafted silica dispersed uniformly in epoxy resin and has an ability to cure the epoxy resin. Glass transition temperature of cured material was much higher than that of the material cured by conventional curing agents. The immobilization of norbornadiene, capsaicin, and flame retardant onto PAMAM-grafted nanoparticle and the properties of the resulting materials are also described.

[doi:10.1295/polymj.PJ2007035]

KEY WORDS Silica Nanoparticles / Carbon Black / Poly(amidoamine) / Surface Grafting / Epoxy Resin / Solvent-Free Dry System / Functional Hybrid Materials /
\end{abstract}

Inorganic nanoparticles, such as silica, calcium carbonate, and titanium dioxide, are widely used industrially as fillers and pigments for polymer materials. Inorganic nanoparticles have excellent properties such as heat-, chemical-, and weather-resistance, lightweight, and low thermal expansion.

Carbon materials, such as carbon black, graphite, vapor-grown carbon fiber, carbon nanotube, and fullerene, are well known as industrially important and commercially available carbon materials. Carbon materials have properties such as electro-conductivity, heat-resistance, biocompatibility, and chemical-resistance. Carbon nanotubes and fullerene attract attention as nanotechnology related materials.

In general, dispersing nanoparticles, such as silica and carbon black, uniformly into a polymer or organic solvent is difficult because of aggregation of the nanoparticles. The mechanical properties of nanocomposite with these nanoparticles are considered to depend not only on the mechanical properties of the polymer matrix, but also properties of interfacial regions between surface of nanoparticles and matrix polymer.

Many researchers, therefore, have extensively stud- ied chemical and physical modifications of the surface of silica nanoparticles, carbon black, and carbon nanotubes. The chemical modification of a surface is permanent, but physical modification is temporary. We have pointed out that the dispersibility of silica nanoparticles, carbon black, and carbon nanotubes is extremely improved by surface grafting of polymers, namely, chemical binding of polymers, onto silica nanoparticles, carbon black, and carbon nanotube surfaces. ${ }^{1-6}$

We have reported grafting of various polymers, such as vinyl polymers, ${ }^{7-10}$ polyesters, ${ }^{11,12}$ polyethers,,${ }^{13,14}$ poly(organophosphazene), ${ }^{15}$ polyurethane,${ }^{16}$ and poly(dimethylsiloxane) ${ }^{17}$ onto the surface of silica nanoparticles and carbon black using surface functional groups as grafting sites. Furthermore, many other researchers have also attempted to graft polymers onto silica nanoparticle and carbon black surfaces. For example, the grafting of polymers from nanoparticles (polymer brush) has been achieved by atom transfer radical polymerization (ATRP) initiated by a system consisting of surface functional groups and transition metal complexes. ${ }^{18-22}$ In situ radical transfer addition

${ }^{\dagger}$ To whom correspondence should be addressed (E-mail: ntsuboka@eng.niigata-u.ac.jp). 
(1) Grafting onto process

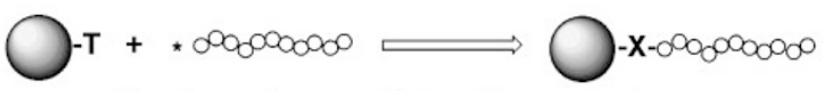

Growing polymer radical, cation, and anion

(2) Grafting from process

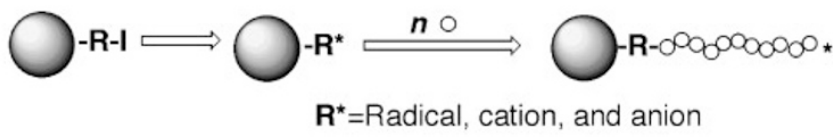

(3) Polymer reaction process

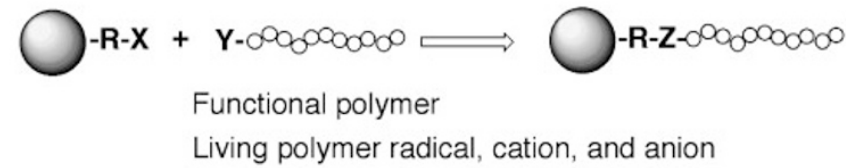

(4) Stepwise growth process

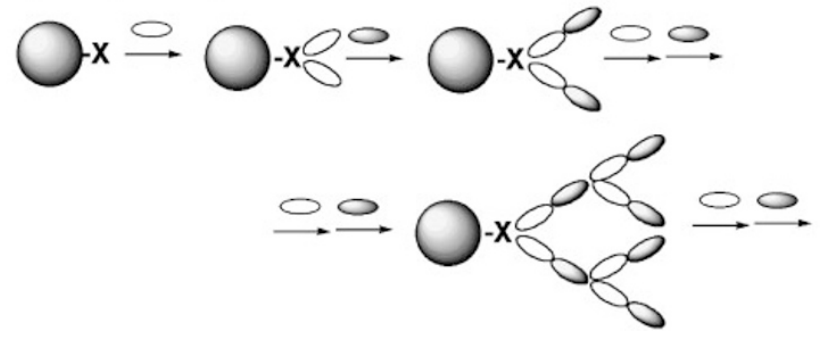

Scheme 1.

polymerization $^{23}$ and emulsion polymerization from silica nanoparticles have been reported. ${ }^{24}$ Wang et $a l$. achieved the synthesis of well-defied organic/inorganic nanocomposite via reverse ATRP. ${ }^{25,26}$ Polymer grafting onto a colloidal silica surface has been reported by Yoshinaga et $a .^{27}$

We pointed out that polymer grafting onto nanoparticle surfaces is of interest for designing new functional organic-inorganic hybrid materials, which have excellent properties of both nanoparticles (as mentioned above) and grafted polymers, including photosensitivity, curing ability, bioactivity, and pharmacological activity. ${ }^{1-6}$

However, scaled-up synthesis of polymer-grafted nanoparticles is difficult to achieve, because complicated reaction processes, such as centrifugation, filtration, and solvent extraction, are required for the synthesis of polymer-grafted nanoparticles, and large amounts of waste solvent are obtained.

In this review, for the prevention of environmental pollution and simplification of reactions, the scaleup synthesis of hyperbranched poly(amidoamine) (PAMAM)-grafted silica nanoparticles and radical graft polymerization of vinyl monomers onto nanoparticle surfaces initiated by surface initiating groups, in a solvent-free dry-system, are summarized. In addition, the immobilization of functional materials, such as norbornadiene, capsaicin, and flame retardant, onto PAMAM-grafted silica nanoparticles is described.

\section{SURFACE GRAFTING OF POLYMERS ONTO NANOPARTICLES: METHODOLOGY}

Several methodologies have been developed for surface grafting of polymers onto nanoparticles. In general, the following principles (Scheme 1) may be applied to prepare polymer-grafted nanoparticles. ${ }^{1-6}$

(1) "Grafting onto" process: graft polymerization of various vinyl monomers is carried out in the presence of nanoparticles using conventional initiators. The grafting of polymers onto the surface proceeds based on termination of growing polymer radicals, cations, and anions formed during the polymerization.

(2) "Grafting from" process: graft polymerization of various monomers is initiated from radical, cationic, and anionic initiating groups previously introduced onto the nanoparticle surface.

(3) Polymer reaction process: grafting onto the nanoparticle surface is achieved by the reaction of functional groups on nanoparticles with polymers containing functional groups such as hydroxyl, carboxyl, and amino groups. In addition, the grafting can be achieved via deactivation of living polymer chain ends by functional groups on the nanoparticle surface.

(4) Stepwise growth process: grafted polymer chains are grown from surface functional groups on 


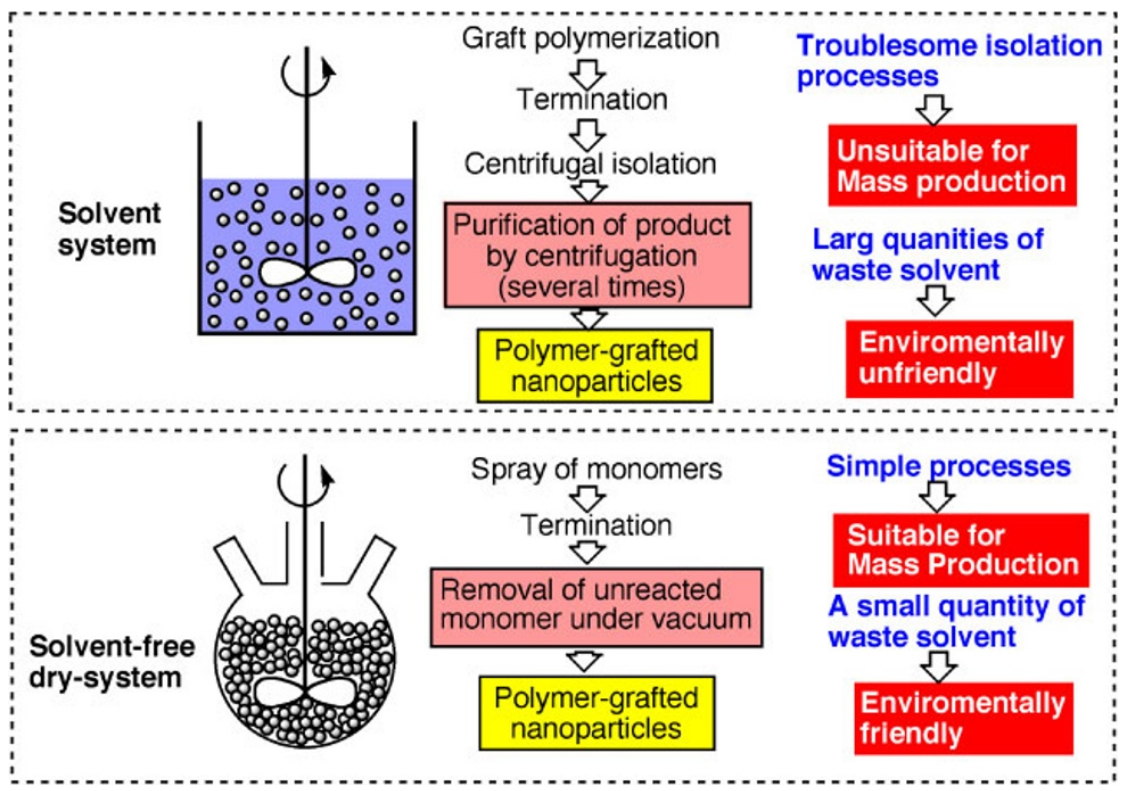

Figure 1. Graft polymerization of polymers onto the nanoparticle surface in a solvent system vs. in solvent-free dry-system.

nanoparticles by repeated reaction of low molecular compounds via dendrimer synthesis methodology.

When process (1) is used, the percentage grafting (i.e., the wt $\%$ of the grafted polymer on the nanoparticle) is less than $10 \%$ due to the preferential formation of ungrafted polymers, although polymer-grafted particles can readily be obtained.

Process (2) is most favorable for the preparation of polymer-grafted nanoparticles with a relatively high percentage of grafting. It is difficult, however, to control the molecular weight and number of grafted polymer chains by use of conventional radical initiating groups. In addition, in the "grafting from" process, it is difficult to prevent the formation of ungrafted polymer, which decreases grafting efficiency due to the chain transfer reaction of growing polymer chains, especially in radical and cationic polymerization. In contrast, grafting of polymers with controlled molecular weight and narrow molecular weight distribution onto nanoparticle surfaces has been successfully achieved by surface-initiated living polymerization. ${ }^{18-26}$

An important characteristic of process (3) is that it offers not only easy control of the molecular weight and the number of chains grafted onto the nanoparticles, but also the possibility of grafting commercially available polymers with a well-defined structure. But the disadvantage of the process is that the number of grafted chains (density of polymer chains) on the surface decreases as the molecular weight of the polymer increases. Polymers with well-defined molecular weights and narrow molecular weight distributions can be grafted via deactivation of living polymer chain ends by functional groups on the nanoparticle surface.
By process (4), hyperbranched polymers having a large number of terminal functional groups can be grafted onto surfaces, although dendron with theoretical structure could hardly be grafted because of steric hindrance.

\section{ADVANTAGES OF GRAFTING IN A SOLVENT-FREE DRY-SYSTEM}

Figure 1 shows a comparison of preparations of polymer-grafted nanoparticles in a solvent-free drysystem with those in a solvent system. In a solvent system, purification and isolation of the resulting nanoparticles involves troublesome procedures such as micro-filtration and centrifugation (over 20,000 $\times$ g). Scale-up synthesis of polymer-grafted nanoparticles was hardly achieved and large quantities of waste organic solvent are obtained.

In a solvent-free dry-system, the isolation of nanoparticles is easily achieved, because untreated monomer can be removed under high vacuum. Therefore, it is concluded that the solvent-free dry-system is environmentally friendly system and it is expected that graft polymerization onto nanoparticle surface in solvent-free dry system should make possible the scaleup synthesis of polymer-grafted nanoparticles.

\section{GRAFTING OF HYPERBRANCHED POLY(AMIDOAMINE) ONTO SILICA NANOPARTICLES IN A SOLVENT-FREE DRY-SYSTEM}

Significant attention has been recently focused on dendrimers as fundamental building blocks which en- 


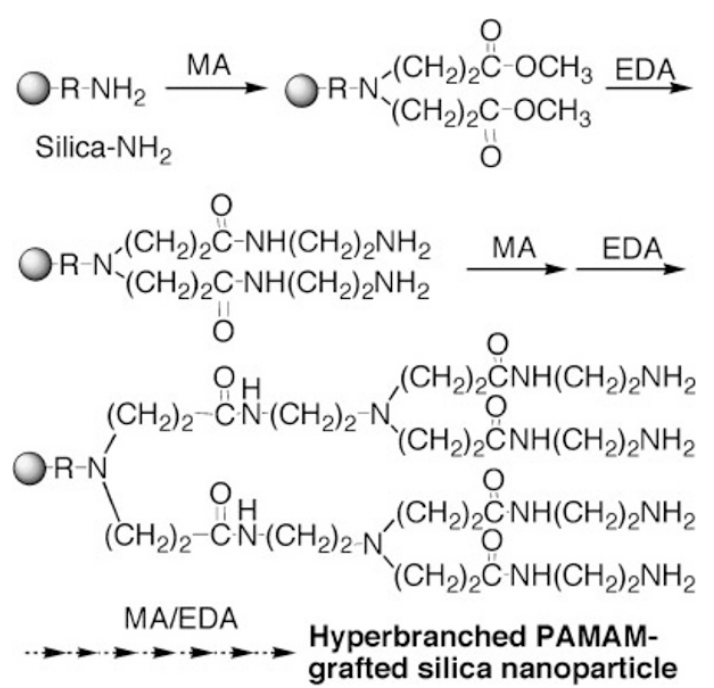

Scheme 2.

able control of molecular weight and branching and versatility in terminal-group modification. ${ }^{28,29} \mathrm{We}$ reported that hyperbranched poly(amidoamine) (PAMAM) can be grown from amino groups on the surface of nanoparticles such as silica, ${ }^{30,31}$ carbon black, ${ }^{32}$ and chitosan powder ${ }^{33}$ using dendrimer synthesis methodology in a methanol solvent.

Grafting of hyperbranched PAMAM onto silica nanoparticles was achieved via repetition of two steps: (1) Michael addition of amino groups on the nanoparticle surface with methyl acrylate (MA) and (2) amidation of terminal methyl ester groups with ethylenediamine (EDA) (Scheme 2). ${ }^{28,29}$ However, complicated procedures are required for the purification and isolation of resulting nanoparticles at each repeated reaction steps. Therefore, the scale-up synthesis of hyperbranched PAMAM-grafted nanoparticles was hardly achieved in methanol.

Instead, we successfully designed a scale-up synthesis for hyperbranched PAMAM-grafted silica nanoparticles in a solvent-free dry-system, ${ }^{34}$ which is carried out as follows.

Introduction of Amino Groups onto Silica Nanoparticles in a Solvent-Free Dry-System

The preparation of grafting sites on the nanoparticle surface by introduction of amino groups was achieved by treatment of surface silanol groups with $\gamma$-aminopropyltriethoxysilane $(\gamma$-APS) in a solvent-free system. ${ }^{34}$ That is, into a $500-\mathrm{mL}$ four-necked flask, as shown in Figure 2, equipped with a mechanical stirrer having a semicircular blade, a thermometer, a purger of argon gas, and a reflux condenser, $15.0 \mathrm{~g}$ of silica nanoparticle were charged and atmosphere was replaced with argon gas. $3.0 \mathrm{~g}$ of ethanol solution of $\gamma$-APS were sprayed onto the silica surface at $150^{\circ} \mathrm{C}$ under agitation at $300 \mathrm{rpm}$. After $30 \mathrm{~min}$, un-

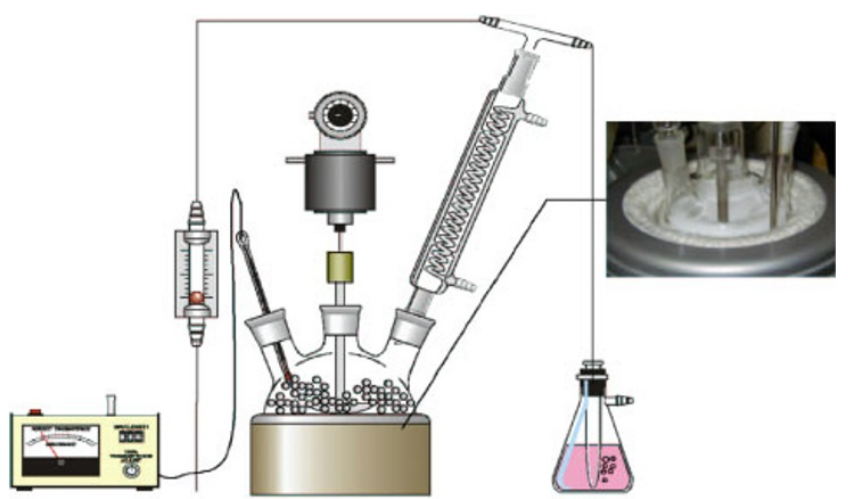

Figure 2. Apparatus for synthesis of polymer-grafted nanoparticles in a solvent-free dry-system.

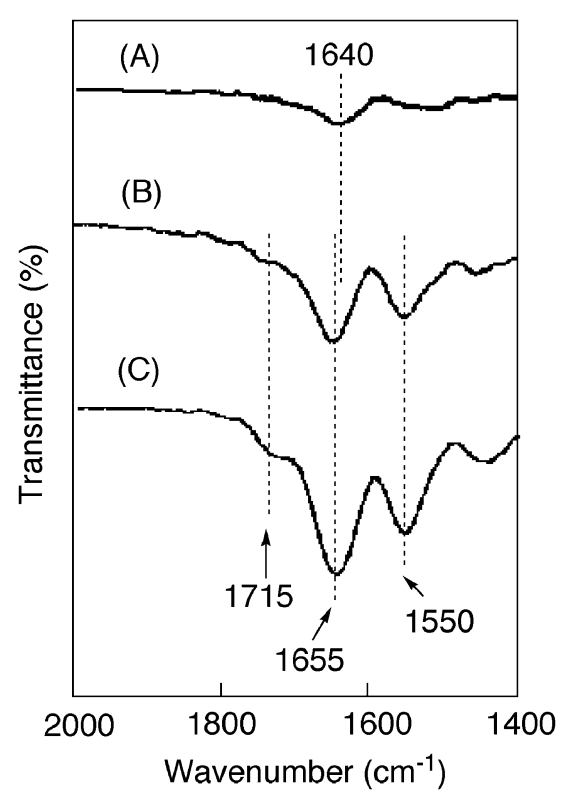

Figure 3. FT-IR spectra of (A) $\gamma$-APS-treated silica nanoparticle, (B) hyperbranched PAMAM-grafted silica nanoparticle with repeated reaction cycles of 3-times (grafting $=38.3 \%$ ), and $(\mathrm{C})$ hyperbranched PAMAM-grafted silica nanoparticle with repeated reaction cycles of 6-times (grafting $=129.4 \%$ ).

reacted $\gamma$-APS and ethanol were removed under high vacuum at $150{ }^{\circ} \mathrm{C}$. The silica nanoparticles thus obtained are abbreviated as Silica- $\mathrm{NH}_{2}$.

Figure 3(A) shows FT-IR spectrum of $\gamma$-APS-treated silica nanoparticle in solvent-free dry-system. The FT-IR spectra of $\gamma$-APS-treated silica nanoparticle show a new absorption at $1640 \mathrm{~cm}^{-1}$, which is characteristic of amino groups. Amino groups may thus be introduced onto the silica surface in a solvent-free drysystem. The number of amino groups introduced onto silica nanoparticle surface was controlled by the concentration of $\gamma$-APS sprayed onto silica nanoparticles.

Grafting of Hyperbranched PAMAM-Grafted Silica Nanoparticles in a Solvent-Free Dry-System

Into a 500-mL four-necked flask, as shown in 
Table I. Grafting of PAMAM onto silica nanoparticle surface in solvent-free dry-systems ${ }^{\mathrm{a}}$

\begin{tabular}{cccccrc}
\hline \multirow{2}{*}{$\begin{array}{l}\text { Cycles of reperated } \\
\text { reaction }\end{array}$} & \multicolumn{2}{c}{ Amino group $(\mathrm{mmol} / \mathrm{g})$} & & \multicolumn{3}{c}{ Grafting $(\%)$} \\
\cline { 2 - 3 } \cline { 5 - 7 } & Experimental & Calcd. & & Experimental & Calcd. & $R^{\mathrm{b}}$ \\
\hline 2-times & 1.7 & 1.3 & & 14.5 & 22.6 & 0.64 \\
4-times & 4.0 & 5.3 & & 69.2 & 112.9 & 0.61 \\
6-times & 7.6 & 21.1 & & 129.4 & 474.0 & 0.27 \\
8-times & 8.8 & 84.5 & & 141.0 & 1918.6 & 0.07 \\
\hline
\end{tabular}

${ }^{\mathrm{a}}$ Amino group content of initiator site, $0.33 \mathrm{mmol} / \mathrm{g} .{ }^{\mathrm{b}} R=$ Experimental value/Calculated value.

Figure 2, containing $15.0 \mathrm{~g}$ of Silica- $\mathrm{NH}_{2}, 3.0 \mathrm{~g}$ of MA (34.8 mmol; excess of surface amino groups) were sprayed and the silica was agitated at $300 \mathrm{rpm}$ at $50^{\circ} \mathrm{C}$ under argon gas. After the reaction for $21 \mathrm{~h}$, unreacted MA was removed under high vacuum at $50{ }^{\circ} \mathrm{C}$. Without isolation of the resulting silica, $3.0 \mathrm{~g}$ of EDA ( $50 \mathrm{mmol}$; excess of surface ester group) were sprayed into the flask, and the reaction was conducted at $50^{\circ} \mathrm{C}$ with agitation. After $21 \mathrm{~h}$, unreacted EDA and methanol formed was also removed under vacuum at $50^{\circ} \mathrm{C}$, and $\mathrm{MA}$ were sprayed again without isolation of the silica. Michael addition and amidation reactions were repeated to grow PAMAM from the silica surface as shown in Scheme 2.

Amino group content of silica nanoparticle and PAMAM grafting onto silica nanoparticle surface (wt $\%$ of grafted polymer on silica) after the grafting reaction is shown in Table I. The amino group content and PAMAM grafting of the resulting silica nanoparticle increased with repeated reaction cycles. With untreated silica nanoparticles, no increase of surface amino group and no grafting of PAMAM onto the surface were observed even after repeated reaction cycles of 8-times.

However, the obtained values for PAMAM grafting and amino group content were considerably smaller than the calculated values. The ratio of experimental value to calculated value, $R$, decreased as the number of reaction cycles increased. The same tendency was observed for grafting of PAMAM onto silica nanoparticles in a methanol solvent system. ${ }^{30-33}$

Figure 3(B) and (C) also show FT-IR spectra of PAMAM-grafted silica nanoparticles with repeated reaction cycles of 3-times and 6-times. The absorption at $1655 \mathrm{~cm}^{-1}$, characteristic of amide group, increased with repeated reaction cycles. The absorption (shoulder) at $1715 \mathrm{~cm}^{-1}$ suggests the presence of ester bonds, indicating the incomplete amidation of terminal methyl ester groups with EDA.

Figure 4 shows FT-IR spectra of PAMAM-grafted silica nanoparticles obtained using a solvent-free dry-system and from a methanol solvent system. ${ }^{30}$ The intensity of the ester bond absorption in the nanoparticles obtained from the solvent-free system is weaker than that of the nanoparticles obtained from

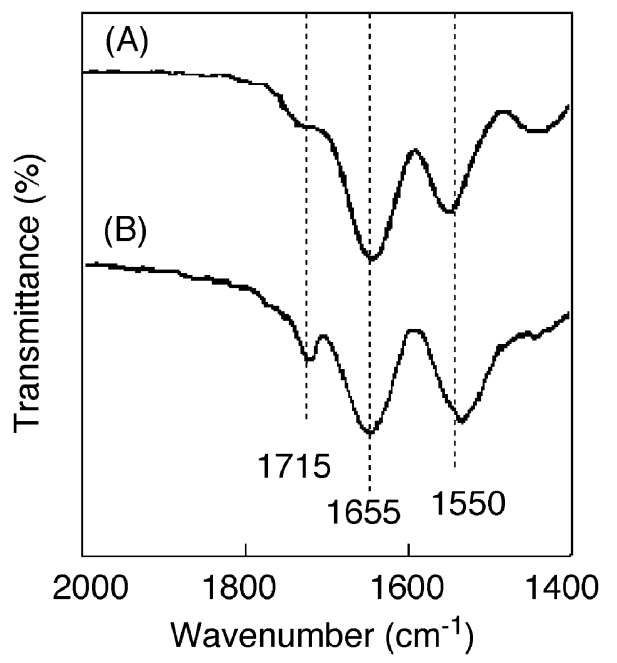

Figure 4. FT-IR spectra of hyperbranched PAMAM-grafted silica nanoparticles with repeated reaction cycles of 6-times (A) in a solvent-free dry-system (grafting $=129.4 \%$ ) and $(B)$ in methanol (grafting $=71.9 \%)$.

the methanol solvent system. This indicates that amidation of the terminal methyl ester groups was more effective in the solvent-free dry-system.

During the grafting reaction, a small amount of ungrafted polymer was formed: the major part, which was methanol-soluble, was hyperbranched PAMAM, while the minor part, which was soluble in THF, was a mixture of polyMA and unknown viscous materials. This indicates that removal of the unreacted monomer in each step was incomplete, probably due to strong adsorption of the monomers on the silica nanoparticle surface.

It may thus be concluded that the theoretical propagation of PAMAM from the silica nanoparticle surface, as shown in Figure 5(A), is hardly achieved, but hyperbranched PAMAM is grafted onto the surface, as schematically shown in Figure 5(B). This may be due to the fact that (1) complete Michael addition and the amidation with surface amino and ester group hardly proceed because of aggregation of silica nanoparticles and (2) the grafted PAMAM chains on the silica surface interfere with the growth of polymer chain from the surface because of steric hindrance. ${ }^{30-33}$ 


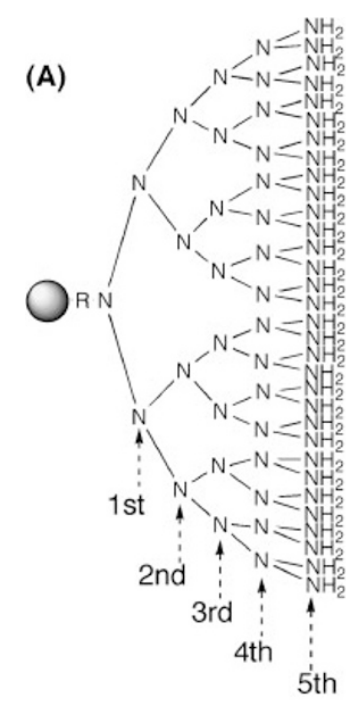

Generation

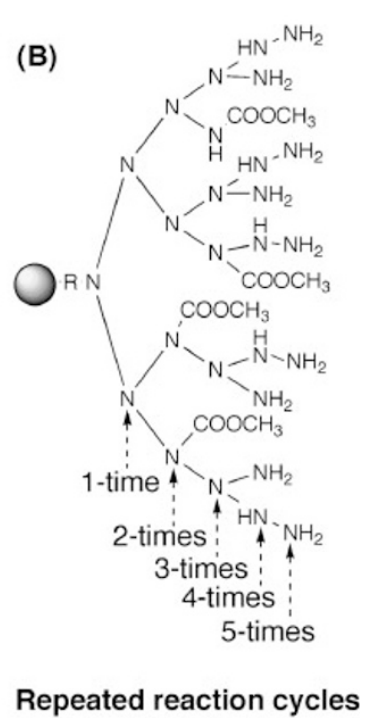

Figure 5. Illustration of (A) theoretical PAMAM dendrongrafted silica nanoparticles and (B) hyperbranched PAMAM-grafted silica nanoparticles obtained with a solvent-free dry-system.

Table II. Effects of amino group content of grafting site on silica nanoparticles on PAMAM grafting in a solvent-free dry-system

\begin{tabular}{ccc}
\hline $\begin{array}{c}\text { Amino group content } \\
(\mathrm{mmol} / \mathrm{g})\end{array}$ & $\begin{array}{c}\text { Grafting }^{\mathrm{a}} \\
(\%)\end{array}$ & $R^{\mathrm{b}}$ \\
\hline 0.12 & 7.2 & 0.88 \\
0.19 & 9.6 & 0.74 \\
0.33 & 14.5 & 0.64 \\
0.45 & 19.8 & 0.64 \\
0.62 & 23.2 & 0.55 \\
\hline
\end{tabular}

${ }^{\mathrm{a}}$ After 2 reaction cycles. ${ }^{\mathrm{b}} R=$ Experimental value/Calculated value.

Effects of Surface Amino Group Content on the Grafting of Hyperbranched PAMAM onto Silica Nanoparticle

Table II shows the effects of amino group content on the grafting of the hyperbranched PAMAM onto silica nanoparticle surface. The percentage of grafting with repeated reaction cycles of 2-times increased with initial amino group content on the surface. However, $R$ (experimental value/theoretical value) decreased with increasing amino group content on the surface as the grafting site. This may be due to the fact that the steric hindrance to surface amino groups increased with increasing density of surface amino groups. ${ }^{30}$

\section{RADICAL GRAFTING OF VINYL POLYMERS ONTO SILICA NANOPARTICLE SURFACE IN A SOLVENT-FREE DRY-SYSTEM}

We reported that radical graft polymerization of vinyl monomers was initiated by azo groups and peroxyester groups previously introduced onto the sur-

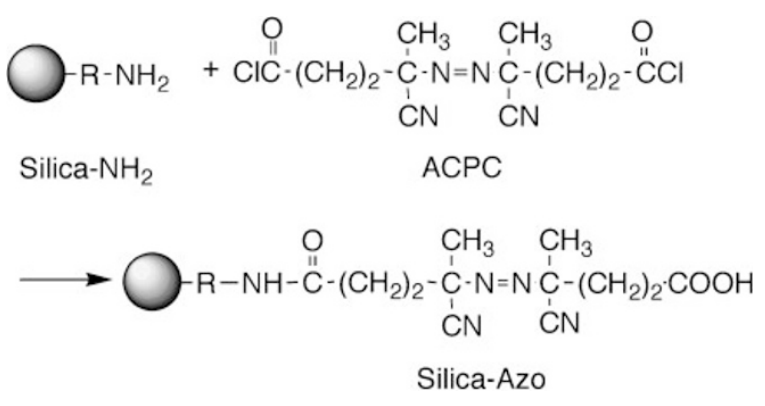

Scheme 3.

Table III. Graft polymerization of vinyl monomers initiated by azo groups introduced onto a silica nanoparticle surface in solvent-free dry-system ${ }^{\mathrm{a}}$

\begin{tabular}{|c|c|c|c|c|c|}
\hline \multirow[b]{2}{*}{ Silica } & \multirow[b]{2}{*}{$\frac{\text { Time }}{\mathrm{h}}$} & \multicolumn{2}{|c|}{ Styrene } & \multicolumn{2}{|c|}{ MMA } \\
\hline & & $\begin{array}{c}\text { Grafting } \\
(\%)\end{array}$ & $\begin{array}{c}\text { Grafting } \\
\text { efficiency } \\
(\%)\end{array}$ & $\begin{array}{c}\text { Grafting } \\
(\%)\end{array}$ & $\begin{array}{c}\text { Grafting } \\
\text { efficiency } \\
(\%)\end{array}$ \\
\hline Untreated & 4 & trace & - & trace & - \\
\hline Silica- $\mathrm{NH}_{2}$ & 4 & trace & - & trace & - \\
\hline Silica-Azo & 1 & 8.5 & 36.0 & 6.0 & 92.3 \\
\hline Silica-Azo & 2 & 11.5 & 55.0 & 6.8 & 98.6 \\
\hline Silica-Azo & 3 & 11.6 & 48.5 & 6.6 & 93.0 \\
\hline Silica-Azo & 4 & 11.5 & 50.2 & 7.0 & 77.8 \\
\hline
\end{tabular}

${ }^{\mathrm{a} S i l i c a-A z o, ~} 8.8 \mathrm{~g}$; monomer, $0.025 \mathrm{~mol}$; Temp., $75^{\circ} \mathrm{C}$.

face of a nanoparticle, such as carbon black and silica, to give the corresponding vinyl polymer-grafted nanoparticle. ${ }^{7-10,35,36}$ During the polymerization in organic solvents, it was confirmed that the grafted polymer chains propagate from the surface radicals formed by the thermal decomposition of azo and peroxyester groups introduced onto the surface. Therefore, we designed the radical graft polymerization of vinyl monomers from silica nanoparticle surface initiated by azo and peroxycarbonate groups in a solventfree dry-system. ${ }^{37}$

Radical Graft Polymerization Initiated by Surface Azo Groups in a Solvent-Free Dry-System

The introduction of azo groups onto the silica nanoparticle surface was achieved by the reaction of surface amino groups with 4,4'-azobis(4-cyanopentanoic chloride) (ACPC) in the presence of pyridine as shown in Scheme 3. ${ }^{8}$ Silica with surface azo groups is abbreviated as Silica-Azo.

Into a $200-\mathrm{mL}$ four-necked flask, as shown in Figure 2, containing $8.8 \mathrm{~g}$ of Silica-Azo, $0.025 \mathrm{~mol}$ of vinyl monomer was sprayed and the silica was agitated at $120 \mathrm{rpm}$ at $75^{\circ} \mathrm{C}$ under argon gas. After the reaction, unreacted monomer was removed under high vacuum.

Table III shows the results of radical graft polymerization of styrene (St) and methyl methacrylate 
(MMA) onto silica nanoparticles, initiated by surface azo groups, in a solvent-free dry-system. When untreated silica nanoparticles and Silica- $\mathrm{NH}_{2}$ were used, grafting of polySt and polyMMA onto the surface was scarcely observed. But in the solvent-free dry-system, azo groups introduced onto the silica surface initiated the radical graft polymerizations of St and MMA. PolySt and polyMMA grafting reached $11.5 \%$ and $7.0 \%$, respectively, at $75^{\circ} \mathrm{C}$ after $4 \mathrm{~h}$.

Figure 6 shows DSC curves of (A) untreated silica, (B) Silica-Azo, (C) ACPA, and (D) polySt-grafted silica nanoparticles. As shown in Figure 6(D), polySt-grafted silica nanoparticles show no exothermic

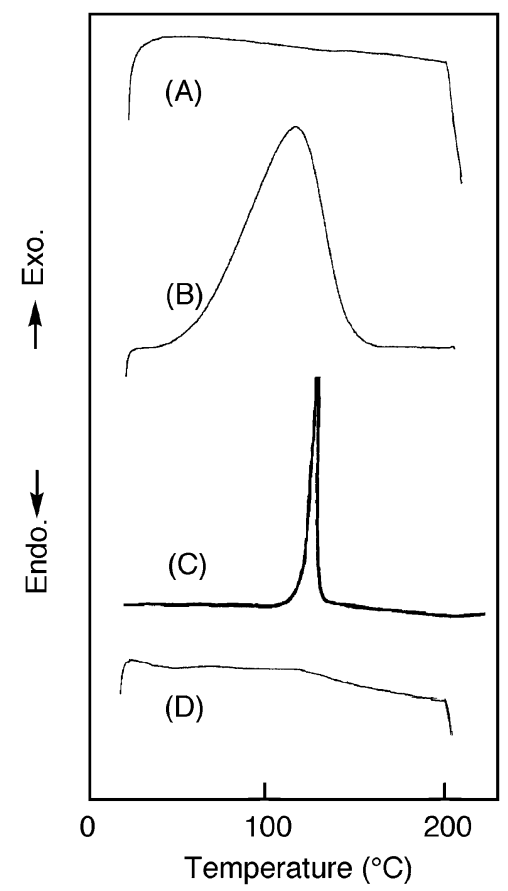

Figure 6. DSC curves of (A) untreated silica nanoparticles, (B) Silica-Azo, (C) ACPA, and (D) Silica-Azo after graft polymerization. peak, indicating that decomposition of the azo groups during polymerization was almost complete.

Figure 7 shows GC-MS of thermally decomposed gas of (A) polySt and (B) polySt-grafted silica nanoparticles. GC of decomposed gas was in agreement with that of polySt. MS of decomposed gas at retention time $2.0 \mathrm{~min}$ was also in agreement with that of polySt. These results clearly show polySt to be grafted onto silica nanoparticle surface.

In a previous paper, we pointed out that grafting efficiency (grafted polymer as a percentage of total polymer formed) during azo-group-initiated graft polymerization in a solvent system was about 50\% at the initial stage of polymerization, but immediately decreased to few percent during the middle and final stages of polymerization. ${ }^{4-7}$ This suggests that polymerization can be initiated by both surface radicals and fragment radicals formed by the thermal decomposition of the surface azo groups: the surface radicals produce surface-grafted polymer, but the fragment radicals produce ungrafted polymer, as shown in Scheme 4. It is thought that during the final stage of graft polymerization, the latter reaction proceeds preferentially, resulting in a decrease in grafting efficiency.

It is interesting to note that the grafting efficiencies of polySt and polyMMA onto the silica surface in the solvent-free dry system were $36-50 \%$ and $90-95 \%$, respectively, as shown in Table III: these values are extremely high, indicating a decrease in the formation of ungrafted polymer by fragment radicals. This may be due to the fact that only surface radicals can initiate polymerization in solvent-free dry-system.

Introduction of Peroxycarbonate Groups onto Silica Nanoparticle Surface by Michael Addition in a Solvent-Free Dry-System and Graft Polymerization

We designed a system in which peroxycarbonate
(A) PolySt

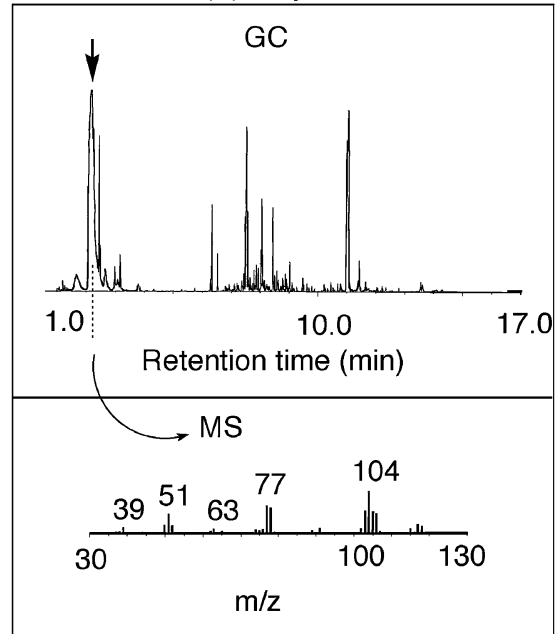

(B) PolySt-grfted

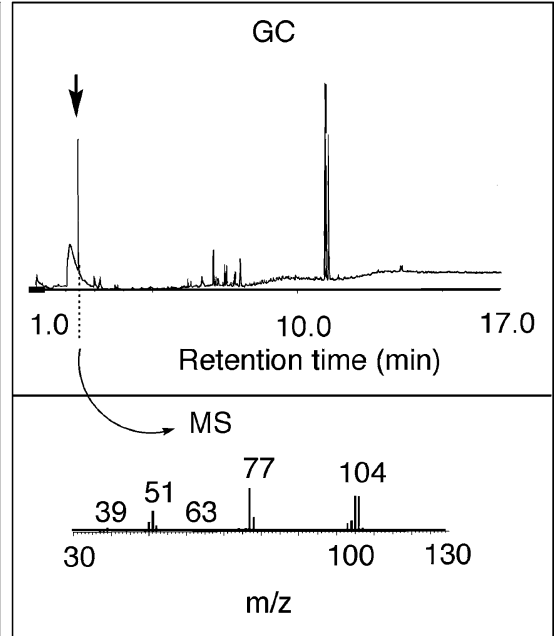

Figure 7. GC-MS of thermal decomposition gas of (A) polySt and (B) polySt-grafted silica nanoparticles. 


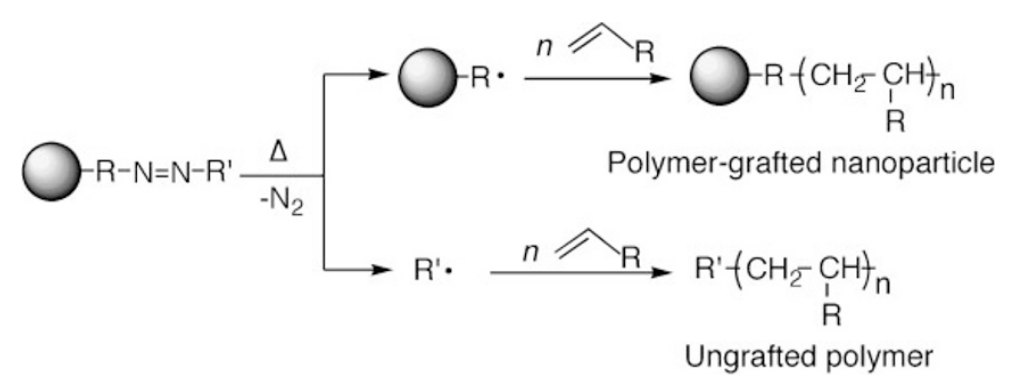

Scheme 4.

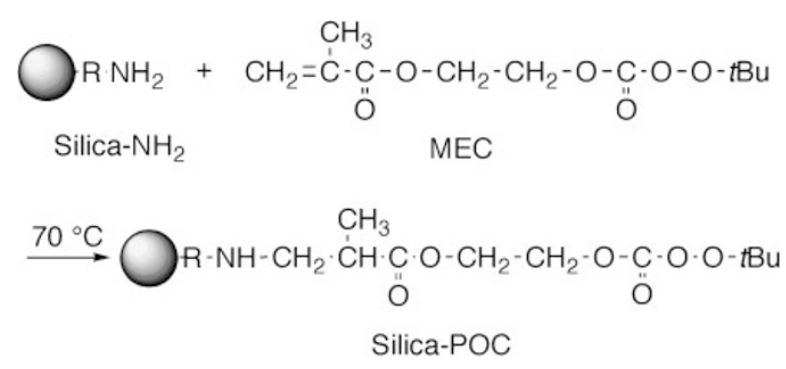

Scheme 5.

Table IV. Introduction of peroxycarbonate groups onto the silica surface by Michael addition of MEC in a solvent-free dry-system

\begin{tabular}{ccc}
\hline Time $(\mathrm{h})$ & Peroxycarbonate group $(\mathrm{mmol} / \mathrm{g})^{\mathrm{a})}$ & $R^{\mathrm{b})}$ \\
\hline 6 & 0.25 & 0.76 \\
24 & 0.21 & 0.64 \\
48 & 0.23 & 0.70 \\
\hline
\end{tabular}

a) Silica- $\mathrm{NH}_{2}, 8.8 \mathrm{~g}$, MEC, $0.022 \mathrm{~mol}$; Temp., $30^{\circ} \mathrm{C}$. b) Rates of amino groups reacted with MEC.

groups could be introduced onto the silica nanoparticle surface by Michael addition of surface amino groups with $t$-butylperoxy-2-methacryloyloxyethylcarbonate (MEC) in a solvent-free dry-system, as shown in Scheme 5. ${ }^{36}$ Into a $200-\mathrm{mL}$ four-necked flask, as shown in Figure 2, containing $8.8 \mathrm{~g}$ of Silica- $\mathrm{NH}_{2}$, $2.5 \mathrm{~g}$ of MEC were sprayed and the silica was agitated at $120 \mathrm{rpm}$ at $30^{\circ} \mathrm{C}$ under argon gas. After the reaction, unreacted MEC was removed under high vacuum. The silica nanoparticles having peroxycarbonate groups obtained are abbreviated as Silica-POC.

The results of this reaction are shown in Table IV. It was found that peroxycarbonate groups were successfully introduced onto the silica nanoparticle surface by Michael addition of amino groups on the surface to MEC: the content of peroxycarbonate groups on the silica nanoparticles reached $0.23 \mathrm{mmol} / \mathrm{g}$, indicating that about $70 \%$ of the introduced amino groups reacted with MEC.

Table V shows the results of radical graft polymerization of vinyl monomers initiated by Silica-POC in a
Table V. Graft polymerization of vinyl monomers initiated by peroxycarbonate groups introduced onto the silica nanoparticle surface in a solvent-free dry-system ${ }^{\mathrm{a}}$

\begin{tabular}{lccc}
\hline Monomer & Time $(\mathrm{h})$ & Grafting $(\%)$ & Grafting efficiency $(\%)$ \\
\hline Styrene & 0.5 & 33.8 & 85.8 \\
Styrene & 1 & 31.0 & 91.1 \\
Styrene & 2 & 32.7 & 95.6 \\
MMA & 2 & 17.4 & 79.2 \\
\hline
\end{tabular}

${ }^{\mathrm{a} S i l i c a-P O C}, 8.8 \mathrm{~g}$, vinyl monomer, $0.025 \mathrm{~mol}$; Temp., $100^{\circ} \mathrm{C}$.

solvent-free system. In the presence of untreated silica nanoparticle and Silica- $\mathrm{NH}_{2}$, vinyl polymer was hardly grafted onto the surface. But the radical graft polymerization of St and MMA was initiated by SilicaPOC in solvent-free dry-system. The percentage of grafting of polySt and polyMMA onto the silica nanoparticle was determined as $32.7 \%$ and $17.4 \%$, respectively. The grafting efficiency was very high.

\section{CATIONIC GRAFTING OF POLYMERS ONTO SILICA NANOPARTICLE SURFACE IN A SOLVENT-FREE DRY-SYSTEM}

We have pointed out that silica nanoparticles containing chloromethyl groups have the ability to initiate cationic ring-opening polymerization of 2-methyl-2oxazoline $(\mathrm{MeOZO})$ to give the corresponding polymer-grafted silica nanoparticles. ${ }^{38}$ It is well known that methyl $p$-toluenesulfonate and methyl iodide can initiate polymerization of $\mathrm{MeOZO} .^{39,40}$ Therefore, we designed a system for grafting of polyMeOZO onto silica nanoparticles by cationic ring-opening polymerization of $\mathrm{MeOZO}$ initiated by methoxysulfonyl and 3-iodopropyl groups on the surface of silica nanoparticles in a solvent-free dry-system (Scheme 6). ${ }^{41}$

The introduction of methoxysulfonyl and 3-iodopropyl groups onto the silica nanoparticle surface was achieved by the treatment of surface silanol groups with 2-(4-methoxysulfonylphenyl)ethyltrimethoxysilane and 3-iodopropyl-trimethoxysilane, re- 

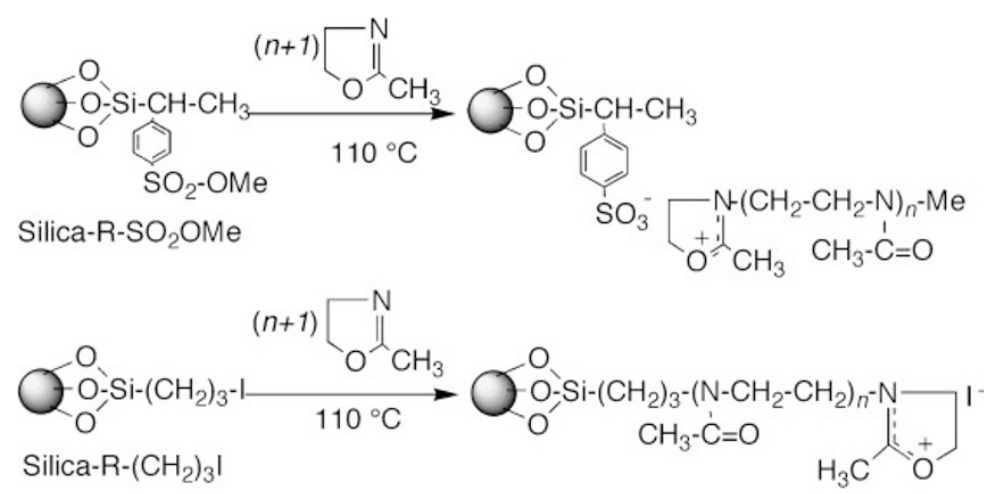

Scheme 6 .

Table VI. Graft polymerization of $\mathrm{MeOZO}$ onto silica nanoparticle surface initiated by methoxysulfonyl group and iodopropyl groups in a solvent-free dry-system

\begin{tabular}{lcccc}
\hline & $\begin{array}{c}\mathrm{MeOZO} \\
(\mathrm{g})\end{array}$ & $\begin{array}{c}\text { Conversion } \\
(\%)\end{array}$ & $\begin{array}{c}\text { Grafting } \\
(\%)\end{array}$ & $\begin{array}{c}\text { Grafting } \\
\text { efficiency } \\
(\%)\end{array}$ \\
\hline Silica $^{\mathrm{a}}$ & 1.8 & 0.0 & 0.0 & - \\
Silica-R-SO $_{2} \mathrm{OMe}^{\mathrm{b}}$ & 7.2 & 90.3 & 23.3 & 14.6 \\
${\text { Silica-R- }\left(\mathrm{CH}_{2}\right)_{3} \mathrm{I}^{\mathrm{c}}}$ & 1.8 & 48.3 & 17.4 & 40.0 \\
& 3.2 & 87.8 & 47.7 & 26.5 \\
& 5.4 & 99.0 & 44.3 & 19.2 \\
\hline
\end{tabular}

${ }^{\mathrm{a}}$ Silica, $2.0 \mathrm{~g} ; 24 \mathrm{~h} ; 110^{\circ} \mathrm{C} .{ }^{\mathrm{b}} \mathrm{Silica}-\mathrm{R}-\mathrm{SO}_{2} \mathrm{OMe}, 4.0 \mathrm{~g} ; 24 \mathrm{~h}$; $110^{\circ} \mathrm{C}$. ${ }^{\mathrm{C}}$ Silica-R- $\left(\mathrm{CH}_{2}\right)_{3} \mathrm{I}, 2.0 \mathrm{~g} ; 24 \mathrm{~h} ; 110^{\circ} \mathrm{C}$.

spectively, in a solvent-free dry-system as above. ${ }^{41}$ The resulting silica nanoparticles having methoxysulfonyl and 3-iodopropyl groups are abbreviated as Silica- $\mathrm{SO}_{2} \mathrm{OMe}$ and Silica- $\left(\mathrm{CH}_{2}\right)_{3} \mathrm{I}$, respectively.

Cationic ring-opening graft polymerization of $\mathrm{MeOZO}$ onto silica nanoparticle surface initiated by Silica- $\mathrm{SO}_{2} \mathrm{OMe}$ and Silica- $\left(\mathrm{CH}_{2}\right)_{3} \mathrm{I}$ in a solventfree dry-system was done as follows. Into a $200-\mathrm{mL}$ four-necked flask, as shown in Figure 2, containing $4.0 \mathrm{~g}$ Silica- $\mathrm{SO}_{2} \mathrm{OMe}$ (Silica- $\left.\left(\mathrm{CH}_{2}\right)_{3} \mathrm{I}\right), \mathrm{MeOZO}$ was sprayed and the silica nanoparticles were agitated at $100 \mathrm{rpm}$ at $110^{\circ} \mathrm{C}$ under argon gas. After the reaction, unreacted $\mathrm{MeOZO}$ was removed under high vacuum.

Table VI shows the results of cationic ring-opening graft polymerization of MeOZO initiated by Silica$\mathrm{SO}_{2} \mathrm{OMe}$ and Silica- $\left(\mathrm{CH}_{2}\right)_{3} \mathrm{I}$ in a solvent-free system. It was found that, as expected, Silica- $\mathrm{SO}_{2} \mathrm{OMe}$ and Silica- $\left(\mathrm{CH}_{2}\right)_{3} \mathrm{I}$ initiated cationic ring-opening polymerization of $\mathrm{MeOZO}$ to give polyMeOZO-grafted silica nanoparticles. The conversion of $\mathrm{MeOZO}$ initiated by Silica- $\left(\mathrm{CH}_{2}\right)_{3} \mathrm{I}$ increased to nearly $100 \%$ with increasing $\mathrm{MeOZO}$ monomer concentration.

This may be due to the fact that in the solvent-free system, polymerization occurs on the silica nanoparticle surface, and consequently, the monomer concentration of the silica surface becomes very high. However, grafting efficiency was found to decrease with

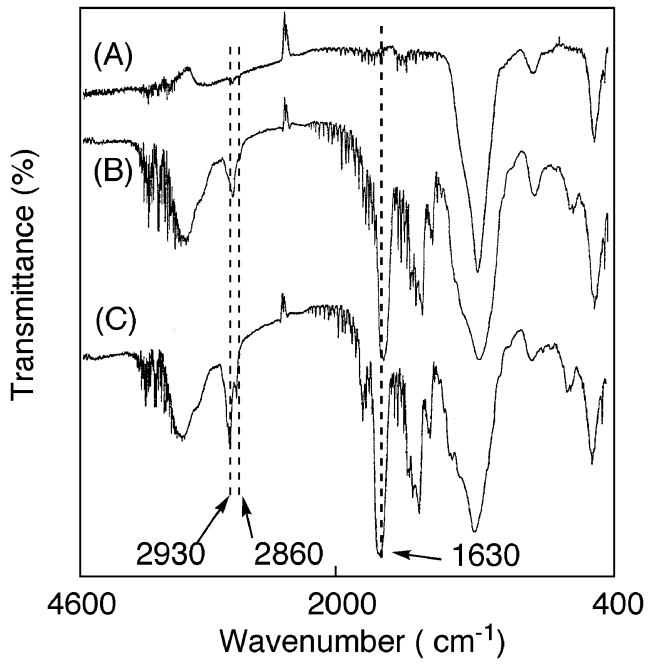

Figure 8. FT-IR spectra of (A) untreated silica nanoparticles, (B) polyMeOZO-grafted silica nanoparticles, and (C) poly$\mathrm{MeOZO}$.

increasing amounts of $\mathrm{MeOZO}$. The results suggest that the proportion of chain transfer reactions increased with increasing MeOZO monomer concentration.

Figure 8 shows FT-IR spectra of (A) untreated silica nanoparticles, (B) polyMeOZO-grafted silica nanoparticles, and (C) polyMeOZO. The FT-IR spectra of polyMeOZO-grafted silica show new absorptions at $1630 \mathrm{~cm}^{-1}, 2860 \mathrm{~cm}^{-1}$ and $2930 \mathrm{~cm}^{-1}$. Absorptions at $2860 \mathrm{~cm}^{-1}$ and $2930 \mathrm{~cm}^{-1}$, which are characteristic of the methylene group of polyMeOZO, were observed. The absorption at $1630 \mathrm{~cm}^{-1}$ is characteristic of the $\mathrm{C}=\mathrm{O}$ bond of polyMeOZO. These results confirm that polyMeOZO was grafted onto the silica nanoparticle surface.

Table VII shows a comparison of cationic ringopening polymerization of $\mathrm{MeOZO}$ on the silica surface in a solvent-free system with that in solution. It is interesting to note that the conversion, percentage grafting, and grafting efficiency in the solvent-free system were greater than those obtained in solution. In addition, grafting efficiency in the solvent-free sys- 
Table VII. Graft polymerization of $\mathrm{MeOZO}$ onto silica surface initiated by iodopropyl group in solution and solvent-free dry-system

\begin{tabular}{ccccc}
\hline & $\begin{array}{c}\text { Time } \\
(\mathrm{h})\end{array}$ & $\begin{array}{c}\text { Conversion } \\
(\%)\end{array}$ & $\begin{array}{c}\text { Grafting } \\
(\%)\end{array}$ & $\begin{array}{c}\text { Grafting } \\
\text { efficiency } \\
(\%)\end{array}$ \\
\hline Dry-system $^{\mathrm{a}}$ & 2 & 98.8 & 44.0 & 22.0 \\
& 6 & 94.0 & 44.5 & 26.2 \\
\hdashline Solution $^{\mathrm{b}}$ & 2 & 0.53 & 9.7 & 25.0 \\
& 6 & 2.1 & 8.6 & 6.4 \\
\hline
\end{tabular}

${ }^{\mathrm{a} S i l i c a-R}-\left(\mathrm{CH}_{2}\right)_{3} \mathrm{I}, 4.0 \mathrm{~g} ; \mathrm{MeOZO}, 7.2 \mathrm{~g} ; 110^{\circ} \mathrm{C}$. ${ }^{\mathrm{b}}$ Silica-R$\left(\mathrm{CH}_{2}\right)_{3} \mathrm{I}, 0.2 \mathrm{~g} ; \mathrm{MeOZO}, 16 \mathrm{~g} ; 110^{\circ} \mathrm{C}$.

tem did not decrease as polymerization progressed. These results suggest that the chain transfer reaction was depressed in the solvent-free system because polymerization occurs on the silica nanoparticle surface.

\section{CATIONIC GRAFTING OF POLYMERS ONTO CARBON BLACK SURFACE IN A SOLVENT-FREE DRY-SYSTEM}

We have reported that carboxyl groups on the surface of carbon black have the ability to initiate cationic ring-opening polymerization of $\mathrm{MeOZO}^{42}$ and cationic polymerization of vinyl monomers such as isobutyl vinyl ether (IBVE) and $N$-vinyl-2-pyrrolidone (NVPD) ${ }^{43-45}$ During cationic polymerization, the polymers were grafted onto the carbon black surface via termination of the growing polymer cations by surface carboxylate groups (counteranions), as shown in Scheme 7. We thus designed cationic grafting of polymers onto carbon black surface initiated by carboxyl groups in a solvent-free dry-system. ${ }^{46}$

Cationic Ring-Opening Polymerization of MeOZO Initiated by Carboxyl Groups on Carbon Black in a Solvent-Free Dry-System

Cationic ring-opening graft polymerization of $\mathrm{MeOZO}$ onto carbon black surface initiated by car-
Table VIII. Graft polymerization of $\mathrm{MeOZO}$ onto carbon black surface initiated by carboxyl groups in a solvent-free dry-system ${ }^{\mathrm{a}}$

\begin{tabular}{ccccc}
\hline & $\begin{array}{c}\text { Monomer } \\
(\mathrm{g})\end{array}$ & $\begin{array}{c}\text { Conversion } \\
(\%)\end{array}$ & $\begin{array}{c}\text { Grafting } \\
(\%)\end{array}$ & $\begin{array}{c}\text { Grafting } \\
\text { efficiency }(\%)\end{array}$ \\
\hline MeOZO & 1.8 & 86.4 & 25.0 & 66.7 \\
& 3.6 & 79.2 & 29.9 & 41.2 \\
& 7.2 & 38.6 & 53.8 & 77.3 \\
\hline
\end{tabular}

${ }^{\mathrm{a}}$ Carbon black, $4.0 \mathrm{~g} ; 24 \mathrm{~h} ; 110^{\circ} \mathrm{C}$.

boxyl groups in a solvent-free dry-system was done the same as above. That is, $\mathrm{MeOZO}$ was sprayed onto carbon black and the reaction was conducted in a solvent-free dry-system to obtain polyMeOZO-grafted carbon black.

The conversion, percentage of grafting, and grafting efficiency of polyMeOZO onto carbon black are shown in Table VIII. It was found that cationic ringopening polymerization of MeOZO was successfully initiated by carboxyl groups on the carbon black surface in the solvent-free system. The percentage of grafting reached $53.8 \%$, and the grafting efficiency increased up to $77.3 \%$ with MeOZO monomer concentration. The conversion, grafting, and grafting efficiency in this solvent-free system were much greater than those in solution. ${ }^{42}$ In addition, the grafting efficiency did not decrease as polymerization progressed. This result suggests that the chain transfer reaction was depressed in the solvent-free system due to the fact that polymerization occurs on the carbon black surface.

Cationic Polymerization of NVPD Initiated by Carboxyl Groups on Carbon Black

Table IX shows the results of carboxyl-group-initiated cationic polymerization of NVPD on carbon black in a solvent-free dry-system. It was found that cationic polymerization of NVPD was successfully initiated by carboxyl groups on the carbon black surface to give poly(NVPD)-grafted carbon black. The percentage grafting was $27.7 \% .^{46,47}$

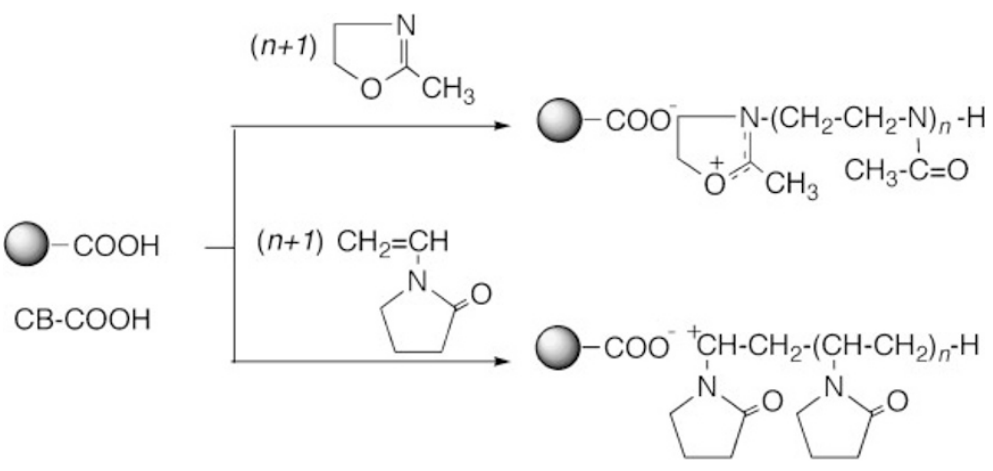

Scheme 7. 
Table IX. Cationic graft polymerization of NVPD initiated by carbon black surface in a solvent-free dry-system ${ }^{\mathrm{a}}$

\begin{tabular}{cccc}
\hline $\begin{array}{c}\text { Monomer } \\
(\mathrm{g})\end{array}$ & $\begin{array}{c}\text { Conversion } \\
(\%)\end{array}$ & $\begin{array}{c}\text { Grafting } \\
(\%)\end{array}$ & $\begin{array}{c}\text { Grafting efficiency } \\
(\%)\end{array}$ \\
\hline 1.8 & 28.3 & 8.0 & 60.8 \\
3.6 & 47.5 & 24.1 & 56.1 \\
7.2 & 56.3 & 27.7 & 27.1 \\
\hline
\end{tabular}

${ }^{\mathrm{a} C a r b o n}$ black, $4.0 \mathrm{~g} ; 24 \mathrm{~h} ; 110^{\circ} \mathrm{C}$.
(A)

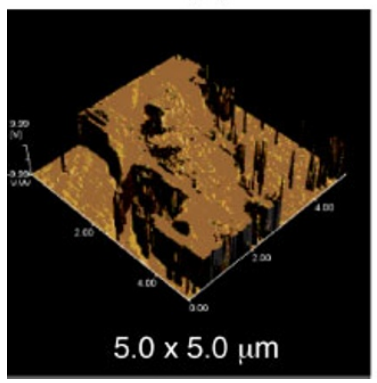

(B)

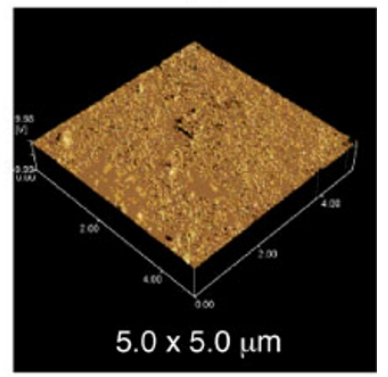

Figure 9. AFM images (phase mode) of the surface of epoxy resin cured by (A) EDA in the presence of untreated silica nanoparticle and (B) Silica-PAMAM: $\mathrm{BF}_{3}$.

\section{CURING OF EPOXY RESIN BY HYPERBRANCHED PAMAM-GRAFTED SILICA NANOPARTICLE}

We have reported that hyperbranched PAMAMgrafted silica containing $\mathrm{BF}_{3}$-amine complex groups (Silica-PAMAM:BF ${ }_{3}$ ) acts as effective curing agent for epoxy resins. ${ }^{48,49} \mathrm{BF}_{3}$ complexation of terminal amino groups of PAMAM-grafted silica was achieved by treatment of PAMAM-grafted silica with a boron trifluoride diethylether complex..$^{50,51}$

Figure 9 shows AFM (phase mode) aspects of (A) the surface of an epoxy resin/silica nanocomposite prepared by curing epoxy resin with Silica-PAMAM: $\mathrm{BF}_{3}$, and $(\mathrm{B})$ that of epoxy resin cured with ethylenediamine (EDA) in the presence of untreated silica. The surface morphology of the latter was found to be rough due to the aggregation of silica nanoparticles, while that of the nanocomposite prepared from Silica-PAMAM: $\mathrm{BF}_{3}$ was very smooth. This result suggests that the Silica-PAMAM:BF $\mathrm{BF}_{3}$ nanoparticles were dispersed and incorporated uniformly, with chemical bonding, into the continuous network of epoxy resin.

The thermal decomposition behavior of the epoxy resin/silica nanocomposite was investigated using TGA, and the result is shown in Figure 10. The $10 \%$ weight loss temperatures of (A) the product cured with Silica-PAMAM:BF 3 and $(B)$ that cured with EDA in the presence of untreated silica were de-

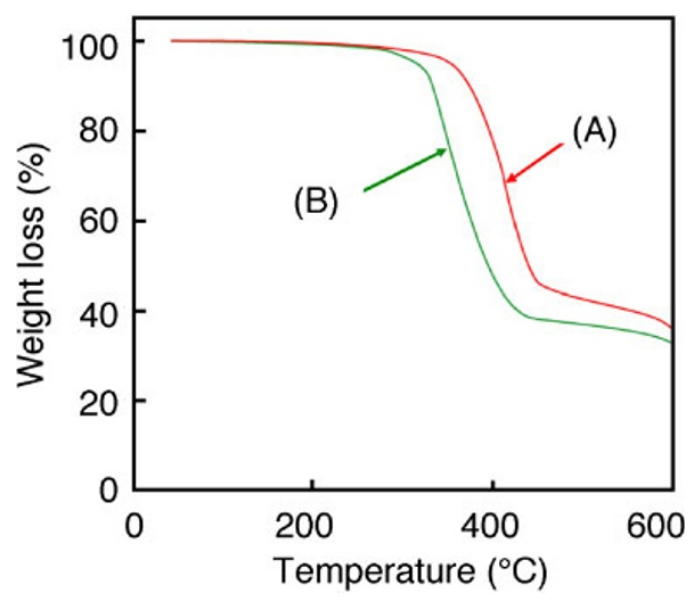

Figure 10. TGA curved of epoxy resin cured by (A) SilicaPAMAM: $\mathrm{BF}_{3}$ and (B) EDA in the presence of untreated silica nanoparticles.

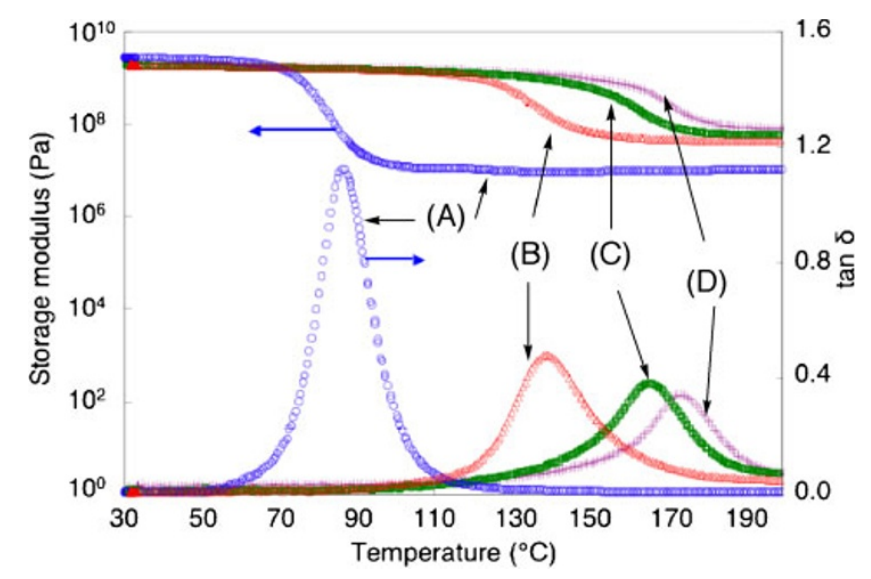

Figure 11. DMA curves of epoxy resin cured by (A) EDA in the presence of untreated silica nanoparticle, (B) SilicaPAMAM:BF 3 (10 wt \%), (C) Silica-PAMAM:BF 3 (20 Wt \%), and Silica-PAMAM:BF 3 (30 wt \%).

termined to be $392^{\circ} \mathrm{C}$ and $348^{\circ} \mathrm{C}$, respectively. This indicates that the thermal decomposition behavior of the product cured with Silica-PAMAM:BF $\mathrm{B}_{3}$ was superior to that cured with EDA.

The temperature dependence of the dynamic mechanical properties of the epoxy resin/silica nanocomposite prepared from PAMAM-grafted silica (repeated reaction cycles of 3-times) containing $\mathrm{BF}_{3}$-amine complex groups is shown in Figure 11. It is interesting to note that the glass transition temperature of the epoxy resin/silica nanocomposite increased with increasing Silica-PAMAM: $\mathrm{BF}_{3}$ content; the glass transition temperature of epoxy resin/silica nanocomposites containing $30 \mathrm{wt} \%$ Silica-PAMAM: $\mathrm{BF}_{3}$ exceeded $170{ }^{\circ} \mathrm{C} .{ }^{49}$ In addition, the storage modulus of these resin/silica nanocomposites was maintained at high values even in high-temperature region. These results suggest that the micro-Brownian motion of the epoxy network is 


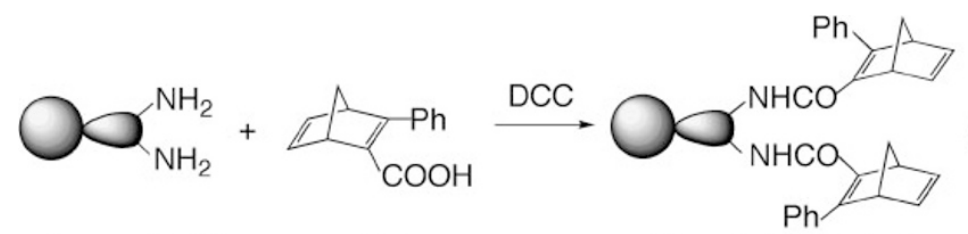

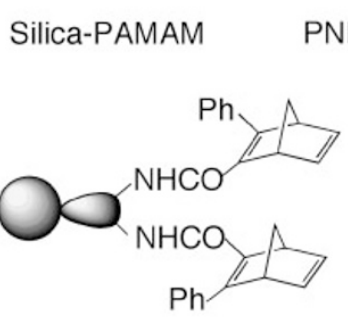

Silica-PAMAM-NBD

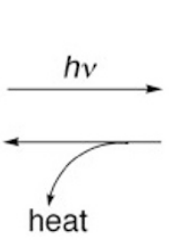

Scheme 8.

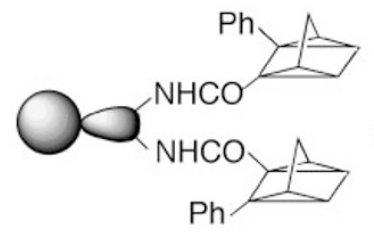

QD-immobilized silica strongly restricted, and the heat resistance of the cured epoxy resin is significantly improved by hybridization with the Silica-PAMAM:BF ${ }_{3}$ in epoxy resin.

\section{IMMOBILIZATION OF NORBORNADIENE ONTO HYPERBRANCHED PAMAPAM- GRAFTED SILICA NANOPARTICLE}

In the development of new energy resources in replace of petroleum, the effective utilization of solar energy is important. For the effective use of sunlight energy, photochemical valence isomerization between norbornadiene (NBD) and quadricyclane (QC) derivatives has been noted for solar energy conversion and storage systems. ${ }^{52-55}$ Photoenergy can be stored as strain energy (about $96 \mathrm{~kJ} / \mathrm{mol}$ ) in QC molecules and the energy can be released as thermal energy upon heating. Nishikubo et al. reported the preparation of polymers having NBD moieties in the main chain or the side chain, their photochemical properties, and reversion to release stored thermal energy in QC polymers. ${ }^{56-61}$

Immobilization of NBD on Hyperbranched PAMAMGrafted Silica Nanoparticles

The immobilization of NBD moieties onto the silica surface by direct condensation between NBD containing carboxyl groups (3-phenyl-2,5-norbornadiene-2carboxylic acid, PNBC) and the surface terminal amino groups of hyperbranched PAMAM-grafted silica in the presence of $\mathrm{N}, \mathrm{N}^{\prime}$-dicyclohexylcarbodiimide (DCC) as a condensing agent was examined as shown in Scheme 8 (1). ${ }^{62}$

Figure 12 shows the effect of reaction time on the immobilization of NBD on hyperbranched PAMAMgrafted silica nanoparticles. It was found that the amount of immobilized NBD moieties increased with reaction time.

Table $\mathrm{X}$ shows the effects of PAMAM grafting on

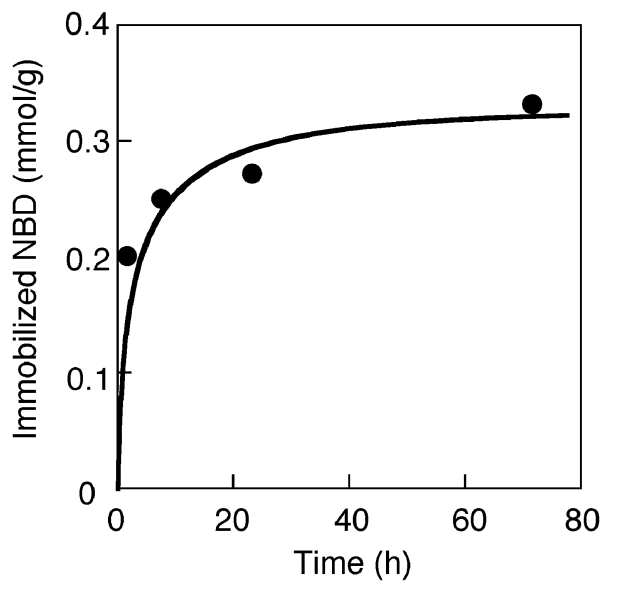

Figure 12. Effects of reaction time on immobilization of NBD moieties onto PAMAM-grafted silica: PAMAM-grafted silica (grafting $=56 \%$ ), $0.20 \mathrm{~g}$; PNBC, $0.10 \mathrm{~g}$; DCC, $0.09 \mathrm{~g}$; $n$ hexane, $25 \mathrm{~mL} ; 30^{\circ} \mathrm{C}$.

Table X. Immobilization of NBD onto various silica surface

\begin{tabular}{|c|c|c|c|}
\hline \multirow{2}{*}{ Silica } & Amino groups & NBD-immobilized & $R$ \\
\hline & $\mathrm{mmol} / \mathrm{g}$ & $\mathrm{mmol} / \mathrm{g}$ & $\%$ \\
\hline Silica- $\mathrm{NH}_{2}$ & 0.6 & 0.25 & 42 \\
\hline PAMAM-grafted & 2.4 & 0.33 & 14 \\
\hline PAMAM-grafted & 5.5 & 0.37 & 7 \\
\hline
\end{tabular}

Silica, $0.20 \mathrm{~g}$; PNBC, $0.10 \mathrm{~g}$; DCC, $0.09 \mathrm{~g}, n$-hexane, $25 \mathrm{~mL}$, $72 \mathrm{~h}, 30^{\circ} \mathrm{C}$.

the immobilization of NBD moieties onto PAMAMgrafted silica. Immobilized NBD moieties onto the silica nanoparticle increased with amino groups and the immobilized NBD moieties were $0.37 \mathrm{mmol} / \mathrm{g}$. But the percentage of amino groups for the immobilization of NBD moieties, $R$, decreased with increasing number of amino groups. The reactivity of terminal amino groups of PAMAM-grafted silica with PNBC may thus decrease with density of surface amino groups, because of steric hindrance. 


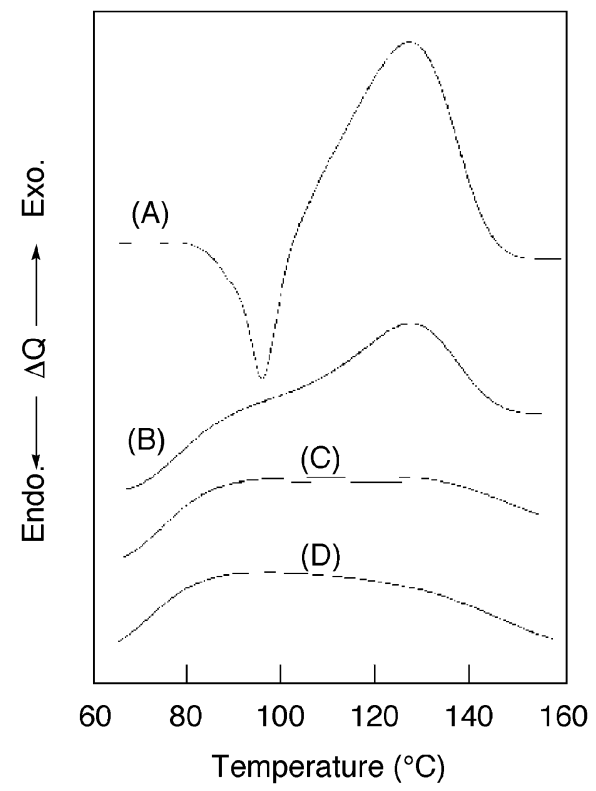

Figure 13. DSC curves of (A) QC, (B) QC-immobilized silica, (C) NBD-immobilized silica, and (D) PAMAM-grafted silica. The scanning rate, purge gas, and purge rate were $5{ }^{\circ} \mathrm{C} / \mathrm{min}$, nitrogen, and $50 \mathrm{~mL} / \mathrm{min}$, respectively.

It is concluded that the direct condensation reaction of carboxyl groups of PNBC with terminal amino groups of PAMAM-grafted silica proceeds and NBD moieties are immobilized onto the terminal amino groups of the hyperbranched PAMAM-grafted silica with amide bond as shown in Scheme 8 (1).

\section{Storage of Solar Energy by Photo-Irradiated NBD-} Immobilized Silica Nanoparticles

The immobilized NBD moieties on the silica surface can be isomerized to QC moieties by photo-irradiation. The release of heat from QC-immobilized silica was determined. Figure 13 shows the DSC curves of (A) QD, (B) photo-irradiated NBD-immobilized silica (QD-immobilized silica), (C) NBD-immobilized silica (without photo-irradiation), and (D) PAMAM-grafted silica. Untreated PAMAM-grafted silica and NBD-immobilized PAMAM-grafted silica without photo-irradiation showed no exothermic

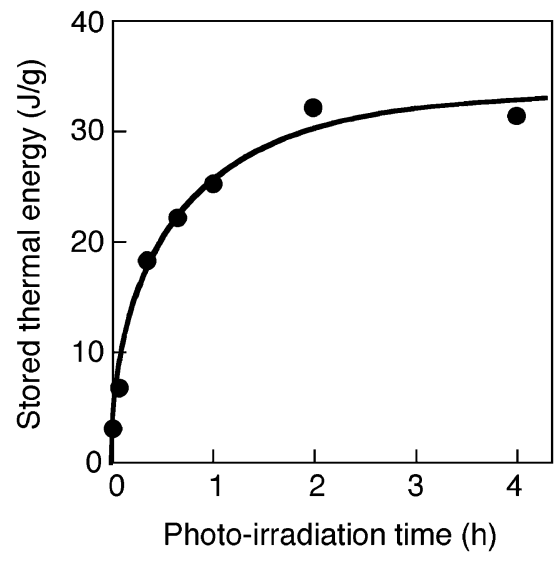

Figure 14. Effects of photo-irradiation time on stored thermal energy of NBD-immobilized silica.

peaks, but QD-immobilized silica showed exothermic peak based on the isomerization of QC moieties to NBD moieties (Scheme 8 (2)).

Figure 14 shows the relationship between photo-irradiation time and the amount of thermal energy stored by QD-immobilized silica. It was found that the stored thermal energy increased with increasing photo-irradiation time, becoming constant (about $30 \mathrm{~J} / \mathrm{g}$-silica) after $2 \mathrm{~h}$. These results indicated that NBD moieties immobilized onto PAMAM-grafted silica may be used as a solar energy conversion and storage material. ${ }^{62}$

\section{APPLICATION OF HYPERBRANCHED PAMAM-GRAFTED NANOPARTICLES AS FUNCTIONAL NANOCOMPOSITES}

Hyperbranched PAMAM-grafted nanoparticles have the potential to be utilized as a support for catalysts and enzymes due to their many terminal amino groups. In addition, we can control the nature of the nanocomposite surface by use of functional polymer-grafted nanoparticles, as shown in Figure 15. For example, we showed that the surface of a nanocomposite prepared from silicone rubber and antibacterial polymer-grafted nanoparticles shows antibacterial properties. ${ }^{63}$

Functional polymer-grafted nanoparticle

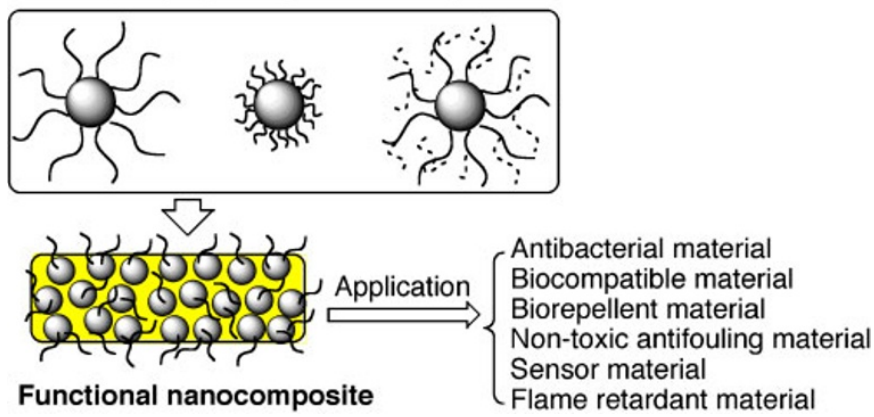

Figure 15. Preparation of functional nanocomposite from bioactive and functional polymer-grafted silica nanoparticles. 
Therefore, it was expected that we could prepare nanocomposites with bioactive and biocompatible surfaces by the corresponding polymer-grafted nanoparticles into conventional polymers, in which nanoparticles act as reinforcing fillers but also as functional materials giving bioactivity to the nanocomposite.

\section{Immobilization of Capsaicin onto Hyperbranched PAMAM-Grafted Silica Nanoparticles}

Marine fouling organisms, such as barnacles and mussels, cause serious problems by settling on ship hulls, fishing equipment, aquaculture cages, and cooling systems for power plants. ${ }^{64}$ In order to protect these marine structures, paints coated with tributyltin compounds have been widely used as antifouling agents. However, tributyltin compounds have been shown to be associated with environmental problems. ${ }^{65}$

Antifouling agents based on natural products have recently been the subject of extensive investigation, with the aim of developing environmentally benign replacements for tributyltin in maritime coating applications. ${ }^{66}$ It was pointed out that capsaicin shows antifouling activity against barnacle cyprids. However, low compatibility and low dispersibility of capsaicin in paints and polymer matrix limits applications of capsaicin in antifouling coatings. ${ }^{67,68}$

We have succeeded in immobilizing capsaicin onto hyperbranched PAMAM-grafted silica nanoparticles via the reaction of capsaicin hydroxyl groups with the terminal isocyanate groups of PAMAM grafted onto a silica surface, which were introduced by treatment with hexamethylene diisocyanate as shown in Scheme 9. The amount of capsaicin immobilized on the hyperbranched PAMAM-grafted silica was determined to be $0.10 \mathrm{mmol} / \mathrm{g} .{ }^{67,68}$

The stimulus activity of capsaicin-immobilized silica was estimated based on a paw-lick test in mice. Capsaicin-immobilized silica dispersed in Tyrode's solution was injected into mouse paws, and amount of time spent paw-licking in $5 \mathrm{~min}$ was measured. The results are shown in Figure 16. When hyper-

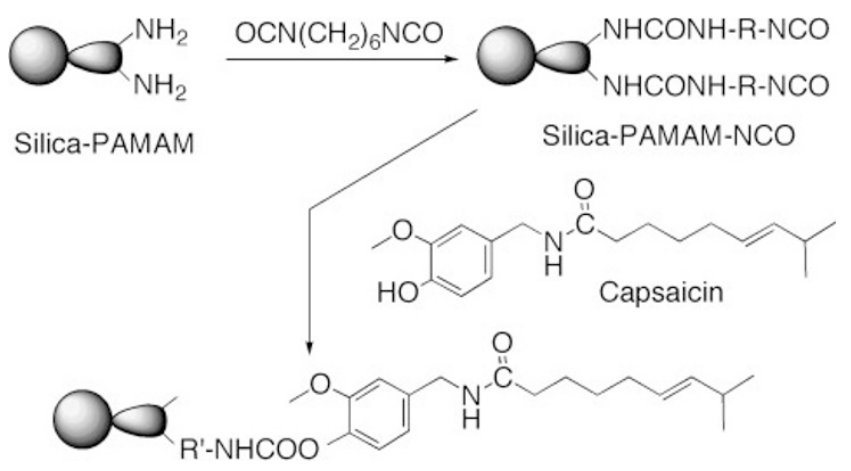

Scheme 9.

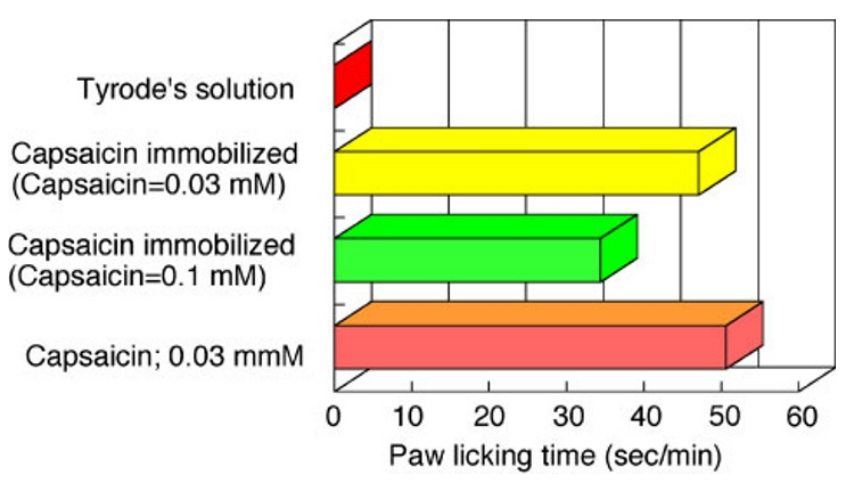

Figure 16. Estimation of stimulus activity of capsaicin-immobilized silica nanoparticles by paw lick test.

branched PAMAM-grafted silica dispersed in Tyrode's solution was injected into mouse paw, no licking of paws was observed; however, when capsaicin-immobilized silica in Tyrode's solution and free capsaicin in Tyrode's solution were injected, the obtained paw-licking times were $57.0 \mathrm{sec} / 5 \mathrm{~min}$ and $50.1 \mathrm{sec} / 5 \mathrm{~min}$, respectively. It was found that the capsaicin retained its stimulus activity even if immobilized onto PAMAM-grafted silica nanoparticles.

\section{Immobilization of Flame Retardant onto Hyper- branched PAMAM-Grafted Silica Nanoparticles}

The main objectives in the development of flameretarding polymers are to increase ignition resistance and to reduce rate of flame spread when incorporated into flammable polymers. Halogenated compounds are good flame retardant additives for polymers, especially when used in combination with antimony trioxide, but halogenated compounds have serious disadvantages in terms of emission of toxic gases, and can act as environmental hormones. ${ }^{69}$ In addition, the applications of the resulting flame retardants were limited due to their compatibility and dispersibility in the polymer matrix.

We investigated the immobilization of halogenated flame retardant on hyperbranched PAMAM-grafted silica nanoparticles. Immobilization of the flame retardant poly(tetrabromobisphenol A)diglycidyl ether (PTBBA) was successfully achieved by reaction of the terminal amino groups of hyperbranched PAMAMgrafted silica with the epoxy groups of PTBBA, as shown in Scheme $10 .^{70}$

Figure 17 shows FT-IR spectra of (A) PAMAMgrafted and (B) PTBBA-immobilized PAMAM-grafted silica. The FT-IR spectrum of the PTBBA-immobilized PAMAM-grafted silica nanoparticles shows absorptions at 1450 and $730 \mathrm{~cm}^{-1}$, which are characteristic of the aromatic rings of PTBBA.

Figure 18 shows the limited oxygen index of epoxy resin filled with (A) untreated silica, (B) untreated 


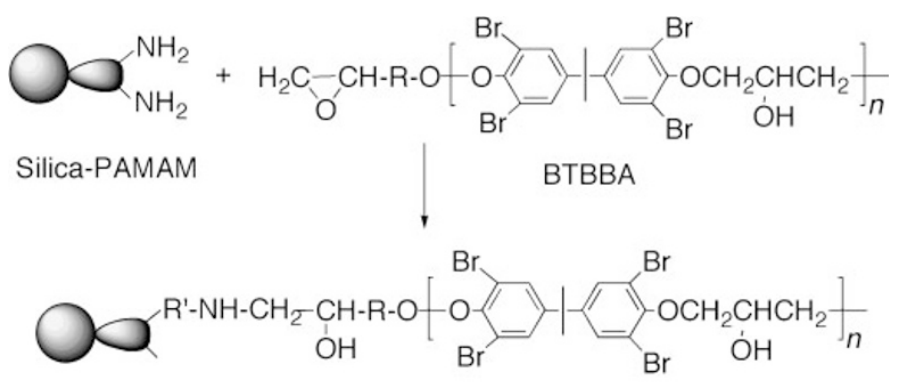

Silica-PAMAM-BTBBA

Scheme 10.

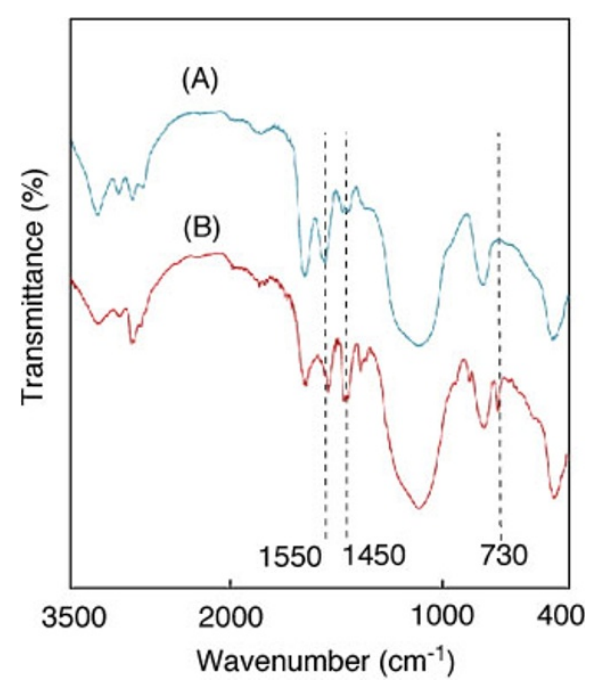

Figure 17. FT-IR spectra of (A) PAMAM-grafted and (B) PTBBA-immobilized PAMAM-grafted silica nanoparticle.

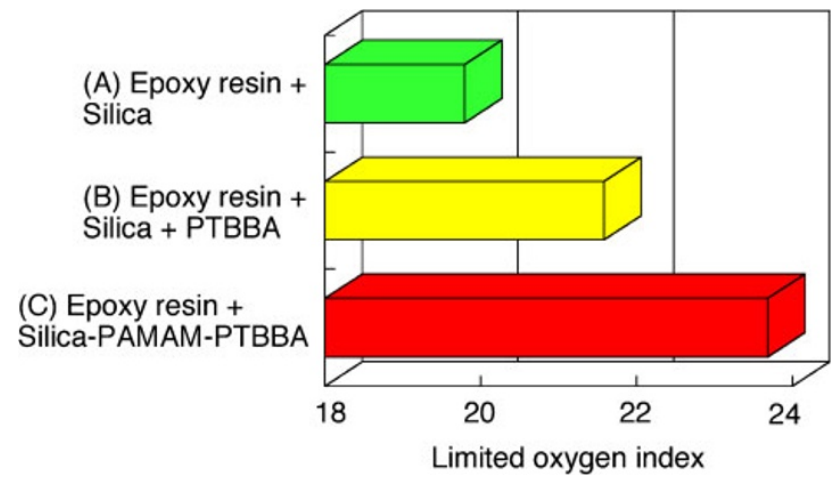

Figure 18. Limited oxygen index of epoxy resin filled with (A) untreated silica, (B) untreated silica and PTBBA, and (C) PTBBA-immobilized PAMAM-grafted silica.

silica and PTBBA, and (C) PTBBA-immobilized PAMAM-grafted silica. The net amount of BTBBA in (B) was adjusted to that of PTBBA immobilized on silica (C). It was found that PTBBA-immobilized PAMAM-grafted silica shows considerably strong flame-retardant properties when compared with nonimmobilized PTBBA.
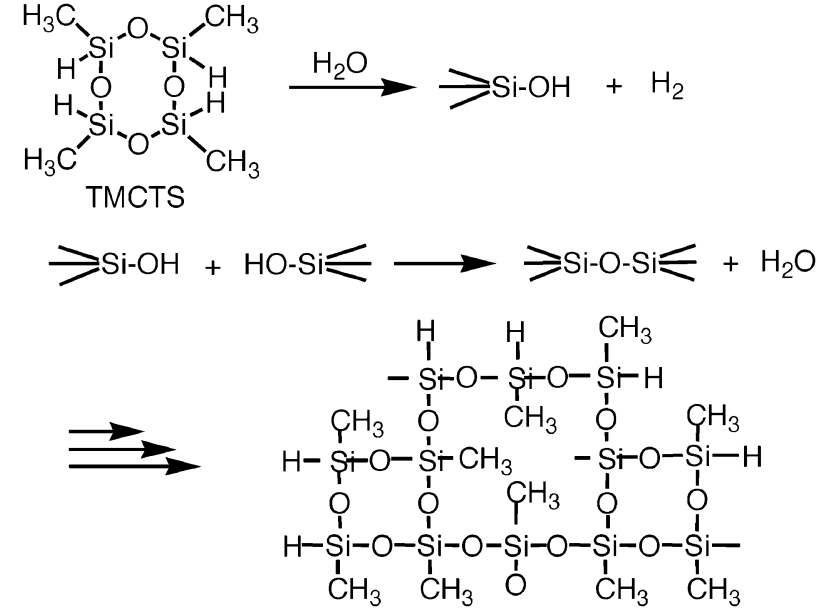

Scheme 11.

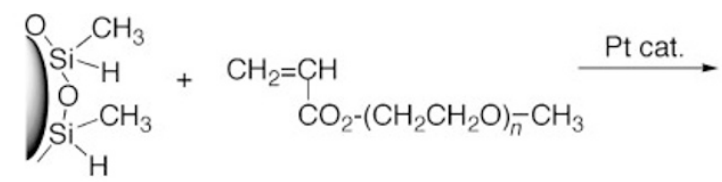

Polysiloxane coated

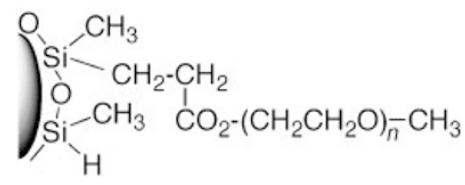

Scheme 12.

\section{CHEMICAL VAPOR DOPOSITION OF POLYSILOXANE ONTO PARTICLE SURFACE}

The functional nano-coating and surface modification of particle surfaces have been reported by Fukui et al. ${ }^{71-74}$ Functional nano-coating is performed by a two-step reaction: 1) polysiloxane coating of the nanoparticle surface (organic pigments, titanium dioxide, or carbon black) using cyclic siloxane by a chemical vapor deposition (CVD) method, as shown in Scheme 11, and 2) addition reaction of the hydrosilyl groups of the polysiloxane-coated thin layer with unsaturated compounds, as shown in Scheme 12. 


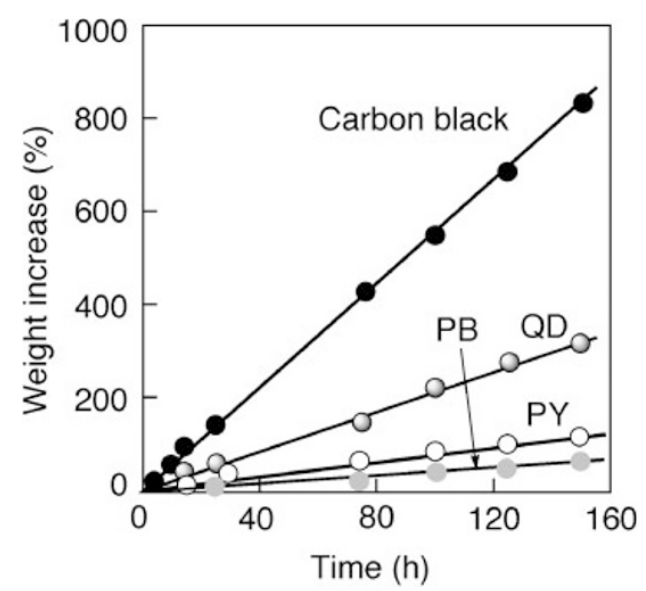

Figure 19. Relationship between reaction time and the amount of polysiloxane coated onto the surfaces of organic pigments and carbon black.

Polysiloxane coating by tetramethylcyclotetrasiloxane (TMCTS) onto particle surface by CVD was readily carried out in a desiccator. $10.0 \mathrm{~mL}$ of TMCTS in a beaker were placed on the bottom of the desiccator, and $1.0 \mathrm{~g}$ of nanoparticles (organic pigments and carbon black) in a Petri dish was put onto the beaker. Polysiloxane coating was carried out at room temperature at normal pressure or under vacuum.

Figure 19 shows the relationship between reaction time and the amount of polysiloxane coated onto the surface of organic pigments and carbon black. Polysiloxane coating was achieved in spite of particle type. ${ }^{75}$ Polysiloxane coating of carbon black progressed quickly, and the deposited polysiloxane was gelated after $12 \mathrm{~h}$; in contrast, the rate of polysiloxane coating of quinacridone (QD) was slower, and the polysiloxane was gelated after $24 \mathrm{~h}$. The rates of polysiloxane coating of phthalocyanine blue (PB) and pigment yellow 180 (PY) were very slow in comparison with those of carbon black and QD. These results were explained as being due to the fact that the surface areas of carbon black and QD are much larger than those of PB and PY.

The surface modification of polysiloxane-coated organic pigments by hydrosilylation with PEG macromonomers was readily achieved, as shown in Scheme 12. The surface of polysiloxane-coated QD shows extremely hydrophobic properties; in contrast, grafting of PEG macromonomer via hydrosilylation resulted in the surface becoming hydrophilic.

\section{CONCLUDING REMARKS}

In this account, recent studies on the grafting of polymers onto nanoparticle surfaces in solvent-free systems are summarized.

Controlled radical polymerization of vapor-phase monomers on a solid surface has also recently been reported. Endo and coworkers reported physically controlled radical polymerization of vapor-phase vinyl monomers by conventional free-radical initiators deposited onto solid surfaces, such as aluminum plate $^{76-79}$ Deposition polymerization in monomer vapor of MMA and styrene was initiated from free radicals on the surface and high molecular weight polymers formed on the substrate surfaces. During polymerization, the number-average molecular weight was found to increase linearly with polymer yield. Consecutive copolymerization led to the formation of block copolymers. They concluded that these results demonstrate the living nature of gas deposition polymerization, in which active species at the ends of growing chains are immobilized on the deposition surface.

Endo et al. also reported photo-induced vaporphase-assisted surface polymerization of vinyl monomers from immobilized free radical initiators on a $\mathrm{Si}$ wafer surface using Fe-based initiating systems. ${ }^{80,81}$

Solid-state grafting onto a carbon black surface has also been reported. Wu et al. reported polymer grafting of natural rubber onto a carbon black surface via a solid-state method; this was achieved by trapping the natural rubber radicals formed in a Haake internal mixer. ${ }^{82}$

As mentioned above, scale-up synthesis of polymer-grafted nanoparticles has heretofore been very difficult to achieve due to the complicated procedures required, such as filtration, centrifugation, and drying to remove by-products formed during the grafting reaction. These inhibit the application of polymer-grated nanoparticles as conventional industrial materials.

The methodologies described herein for the preparation of polymer-grafted nanoparticles in solvent-free dry systems, and by vapor phase and solid phase grafting, are to be applied to the grafting of polymers onto the surface of various nanoparticles. Industrial applications of polymer-grafted nanoparticles may likely be expanded in the future.

Acknowledgment. The author thanks all contributing co-workers and acknowledges the financial support in part by Grant-in-Aid for Scientific Research from the Ministry of Education, Culture, Sports, and Science and Technology of Japan (No. 19560691) and Grant for Promotion of Niigata University Research Projects.

\section{REFERENCES}

1. N. Tsubokawa, Prog. Polym. Sci., 17, 417 (1992).

2. N. Tsubokawa, Modification of Inorganic particles by Grafting of Functional Polymers, in "Fundamental and Applied 
Aspects of Chemically Modified Surface," J. P. Blits and C. B. Little, Ed., Royal Society of Chemistry, London, 1999 , p 36.

3. N. Tsubokawa, Bull. Chem. Soc. Japan, 75, 2115 (2002).

4. N. Tsubokawa, Polym. J., 37, 637 (2005).

5. N. Tsubokawa, Mater. Sci. Technol., 42, 284 (2005).

6. a) N. Tsubokawa, J. Jpn. Soc. Colour Mater., 80, 26 (2007). b) N. Tsubokawa, J. Jpn. Soc. Colour Mater., 80, 215 (2007).

c) N. Tsubokawa, J. Jpn. Soc. Colour Mater., 80, 267 (2007).

7. N. Tsubokawa, K. Fujiki, and Y. Sone, Polym. J., 20, 213 (1988).

8. N. Tsubokawa, A. Kogure, K. Maruyama, Y. Sone, and M. Shimomura, Polym. J., 22, 827 (1990).

9. K. Fujiki, N. Tsubokawa, and Y. Sone, Polym. J., 22, 661 (1990).

10. N. Tsubokawa and H. Ishida, Polym. J., 24, 809 (1992).

11. N. Tsubokawa, A. Funaki, Y. Hada, and Y. Sone, J. Polym. Sci., Polym. Chem. Ed., 20, 3297 (1982).

12. N. Tsubokawa, A. Yamada, and Y. Sone, Polym. Bull., 10, 63 (1983).

13. N. Tsubokawa, H. Nunokawa, and Y. Sone, J. Macromol. Sci., Pure Appl. Chem., A23, 105 (1986).

14. N. Tsubokawa, Y. Jian, and Y. Sone, J. Polym. Sci., Polym. Chem. Ed., 26, 2715 (1988).

15. N. Tsubokawa and H. Tsuchida, J. Macromol. Sci., Pure Appl. Chem., A29, 311 (1992).

16. N. Tsubokawa, H. Matsumoto, and Y. Sone, J. Polym. Sci., Polym. Chem. Ed., 20, 1943 (1982).

17. N. Tsubokawa and K. Yanadori, Kobunshi Ronbunshu, 49, 865 (1992).

18. J. Pyun and K. Matyjaszewski, Chem. Matter., 13, 3436 (2001).

19. K. Ohno, K. Koh, Y. Tsuji, and T. Fukuda, Macromolecules, 35, 8989 (2002).

20. T. Lui, S. Jia, T. Kowalewski, K. Matyjaszewski, R. Casadio-Portilla, and J. Belmont, Langmuir, 19, 6342 (2003).

21. A. E. Harrak, G. Carrot, J. Oberdisse, J. Jestin, and F. Bou, Polymer, 46, 1095 (2005).

22. T. Lui, R. Casadio-Portilla, J. Belmont, and K. Matyjaszewski, J. Polym. Sci., Part A: Polym. Chem., 43, 4695 (2005).

23. P. Liu, M. W. Liu, and Q. J. Xue, Eur. Polym. J., 40, 267 (2004).

24. X. Ding, J. Zhao, Y. Liu, H. Zhang, and Z. Wang, Mater. Lett., 58, 3126 (2004).

25. Y.-P. Wang, X.-W. Pei, Z.-Y. He, and K. Yuan, Eur. Polym. J., 41, 1326 (2005).

26. Y.-P. Wang, X.-W. Pei, and K. Yuan, Mater. Lett., 59, 520 (2005).

27. K. Yoshinaga and M. Teramoto, Bull. Chem. Soc. Jpn., 69, 2667 (1996).

28. D. A. Tomalia, H. Baker, J. Dewald, M. Hall, G. Kallos, S. Martin, J. Roeck, J. Ryder, and P. Smith, Polym. J., 17, 117 (1985).

29. D. A. Tomalia, V. Berry, M. Hall, and D. M. Hedstrand, Macromolecules, 20, 1164 (1987).
30. N. Tsubokawa, H. Ichioka, T. Satoh, S. Hayashi, and K. Fujiki, React. Funct. Polym., 37, 75 (1988).

31. K. Fujiki, M. Sakamoto, T. Satoh, and N. Tsubokawa, J. Macromol. Sci., Pure Appl. Chem., A37, 357 (2000).

32. N. Tsubokawa, T. Satoh, M. Murota, S. Sato, and H. Shimizu, Polym. Adv. Technol., 12, 569 (2001).

33. N. Tsubokawa and T. Takayama, React. Funct. Polym., 43, 341 (2000).

34. M. Murota, S. Sato, and N. Tsubokawa, Polym. Adv. Technol., 13, 144 (2002).

35. S. Hayashi and N. Tsubokawa, J. Macromol. Sci., Pure Appl. Chem., A35, 1781 (1988).

36. S. Hayashi, Y. Takeuchi, E. Eguchi, T. Iida, and N. Tsubokawa, J. Appl. Polym. Sci., 71, 1491 (1999).

37. J. Ueda, S. Sato, A. Tsunokawa, T. Yamauchi, and N. Tsubokawa, Eur. Polym. J., 41, 193 (2005).

38. N. Tsubokawa, Polym. Bull., 22, 55 (1989).

39. T. Saegusa, T. Ikeda, and H. Fujii, Polym. J., 3, 35 (1972).

40. T. Saegusa, T. Ikeda, and H. Fujii, Polym. J., 3, 176 (1972).

41. J. Ueda, T. Onozuka, T. Yamauchi, and N. Tsubokawa, presented at the 8th SPSJ International Polymer Conference, Fukuoka International Congress Center, Fukuoka, Japan, July 26-29, 2005.

42. N. Tsubokawa, I. Asano, and Y. Sone, Polym. Bull., 18, 377 (1987).

43. N. Tsubokawa, N. Takeda, and K. Kudoh, Carbon, 18, 163 (1980).

44. N. Tsubokawa, N. Takeda, and K. Kudoh, Nippon Kagaku Kaishi, 1264 (1980).

45. N. Tsubokawa, N. Takeda, and T. Iwasa, Polym. J., 13, 1093 (1981).

46. J. Ueda, T. Yamauchi, K. Shirai, and N. Tsubokawa, Polym. Prepr. Jpn., 54, 2706 (2005).

47. J. Ueda, K. Fujiki, T. Yamauchi, N. Tsubokawa, and K. Fujiki, presented at Recent advancement of Interfacial Materials Science on Composite Materials, 2007.

48. M. Okazaki, M. Murota, Y. Kawaguchi, and N. Tsubokawa, J. Appl. Polym. Sci., 80, 573 (2001).

49. M. Ukaji, Y. Imai, T. Yamauchi, K. Shirai, and N. Tsubokawa, Polym. Prepr. Jpn., 54, 2708 (2005).

50. E. H. Brown and C. A. Krans, J. Am. Chem. Soc., 51, 2690 (1929).

51. K. Saeki and T. Kamon, Kogyo Kagaku Kaishi, 74, 2197 (1971).

52. R. R. Hautala, R. B. King, and C. Kutal, in "Solar Energy," Hamana Clifton, New Jersey, 1797, p 333.

53. R. B. King and E. M. Sweet, J. Org. Chem., 44, 385 (1979).

54. Z. Yoshida, Heterocycles, 21, 331 (1984).

55. K. Maruyama and H. Tomiaki, J. Org. Chem., 51, 602 (1986).

56. T. Nishikubo, T. Shimokawa, and A. Sahara, Macromolecules, 22, 8 (1989).

57. T. Iizawa, C. Hijikata, and T. Nishikubo, Macromolecules, 25, 21 (1992).

58. T. Nishikubo, T. Kawashima, and S. Watanabe, J. Polym. Sci., Polym. Chem. Ed., 31, 1659 (1993).

59. I. Nishimura, A. Kameyama, T. Sakurai, and T. Nishikubo, Macromolecules, 29, 3818 (1996).

60. A. Tubata, T. Uchiyama, A. Kameyama, and T. Nishikubo, 
Macromolecules, 30, 5649 (1996).

61. T. Iizawa and T. Nishikubo, in "Norbornadiene Polymers," Polymeric Materials Encyclopedia 6, CRC Press, New York, 1966, p 4624.

62. N. Tsubokawa, K. Kotama, H. Saitoh, and T. Nishikubo, Compos. Interfaces, 10, 609 (2003).

63. a) R. Yamashita, Y. Takeuchi, H. Kikuchi, K. Shirai, T. Yamauchi, and N. Tsubokawa, Polym. J., 38, 744 (2006).

b) Y. Takeuchi, W. Gang, K. Shirai, T. Yamauchi, and N. Tsubokawa, presented at Recent Advancement of Interfacial Materials Science on Composite Materials, 2007.

64. M. D. Richmond and R. Seed, Biofouling, 2, 151 (1991)

65. D. V. Ellis and Mar. Pollut, Bull, 22, 8 (1991).

66. Y. Nogata, Y. Kitano, E. Yoshimura, K. Shinshima, and I. Sakaguchi, Biofouling, 20, 87 (2004).

67. T. Saitoh, K. Shirai, T. Yamauchi, and N. Tsubokawa, Polym. Prepr. Jpn., 55, 596 (2006).

68. T. Saitoh, W. Gang, K. Shirai, T. Yamauchi, and N. Tsubokawa, presented at Recent Advancement of Interfacial Materials Science on Composite Materials, 2007.

69. A. K. Sen, B. Mukharjee, A. S. Bhattacharya, L. K. Sanghi, P. P. De, and K. Bhowmik, J. Appl. Polym. Sci., 43, 1673 (1991).

70. a) A. Yuuki, K. Shirai, T. Yamauchi, and N. Tsubokawa, Polym. Prepr. Jpn., 55, 595 (2006). b) A. Yuuki, T. Yamauchi, and N. Tsubokawa, presented at Recent Advancement of Interfacial Materials Science on Composite Materials, 2007.

71. T. Suhara, H. Fukui, and M. Yamaguchi, J. Jpn. Soc. Colour Mater., 67, 489 (1994).

72. T. Suhara, H. Fukui, and F. Suzuki, J. Jpn. Soc. Colour Mater., 68, 597 (1995).

73. N. Tsubokawa, K. Kawatsura, T. Kanemura, and H. Fukui, J. Jpn. Soc. Colour Mater., 71, 156 (1998).

74. H. Fukui, J. Jpn. Soc. Colour Mater., 76, 503 (2003).

75. M. Seki and N. Tsubokawa, unpublished result.

76. M. Yasutake, S. Hiki, Y. Andou, H. Nishida, and T. Endo, Macromolecules, 36, 5974 (2003).

77. M. Yasutake, Y. Andou, S. Hiki, H. Nishida, and T. Endo, J. Polym. Sci., Part A: Polym. Chem., 42, 2621 (2004).

78. M. Yasutake, Y. Andou, S. Hiki, H. Nishida, and T. Endo, Macromol. Chem. Phys., 205, 492 (2004).

79. Y. Andou, H. Nishida, and T. Endo, Chem. Commun., 5018 (2005).

80. Y. Andou, M. Yasutake, J. Jeong, H. Nishida, and T. Endo, Macromol. Chem. Phys., 206, 1778 (2005).

81. Y. Andou, M. Yasutake, J. Jeong, M. Kaneko, H. Nishida, and T. Endo, J. Appl. Polym. Sci., 103, 1879 (2007).

82. H. Xu, B. Li, and C. Wu, Polym. J., 38, 807 (2006).

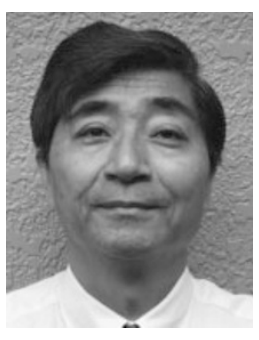

Norio Tsubokawa was born in 1947 in Toyama Prefecture, Japan. He received his M.S. Eng. from Niigata University in 1972. He was appointed research associate of the Department of Applied Chemistry, Faculty of Engineering at Niigata University in 1972. He received his PhD. degree in 1982 from Tokyo Institute of Technology. He was promoted to Associate Professor of the same Department in 1988 and Professor of Department of Material Science and Technology, Faculty of Engineering at Niigata University in 1995. He has received several awards, including the Toyama Award (1990), Award of Society of Rubber Industry, Japan, for the Outstanding Paper published in the Journal of Society of Rubber Industry, Japan (1991), Award of Japan Society of Color Material, Japan, for the Outstanding Paper published in the Journal of Japan Society of Color Material (1993), Ishikawa Carbon Award (1995), Nakanishi Memorial Award (2002), and SPSJ Mitsubishi Chemical Award (2006). His research has been focused on the surface modification and functionalization of nanoparticles and nanocarbons by polymer grafting. 